
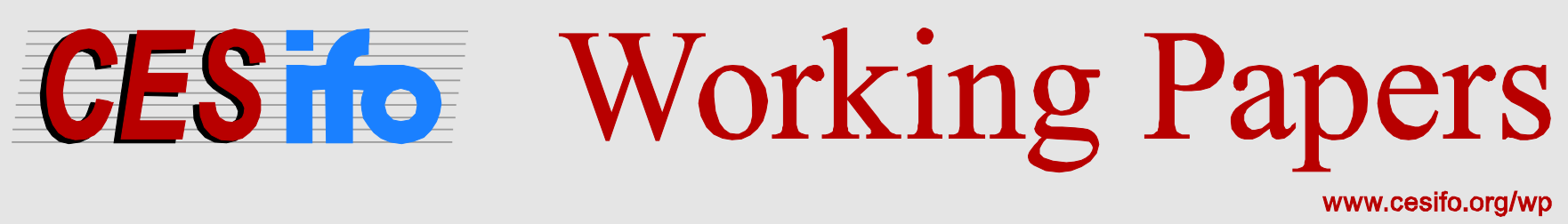

\title{
Resolving Intergenerational Conflict over the Environment under the Pareto Criterion
}

\author{
Torben M. Andersen \\ Joydeep Bhattacharya \\ Pan Liu
}

\begin{abstract}
CESIFO WORKING PAPER NO. 6053
CATEGORY 9: RESOURCE AND ENVIRONMENT ECONOMICS

August 2016
\end{abstract}

An electronic version of the paper may be downloaded

- from the SSRN website:

- from the RePEc website:

- from the CESifo website: WwW.SSRN.com

www.RePEc.org

www.CESifo-group.org/wp

ISSN 2364-1428 


\title{
Resolving Intergenerational Conflict over the Environment under the Pareto Criterion
}

\begin{abstract}
We describe a "business as usual" (BAU) economy in which pollution is a by-product of productive activity by the current generation but "damages" production for future generations. Over time, conditions in the BAU economy become dire: it gets increasingly polluted, consumption falls and generational welfare levels decline. A government introduces costly pollution abatement and finances it via distorting taxes and borrowing on perfect international markets. Pollution levels start to decline, generating downstream welfare gains, some of which the government taxes away, without hurting anyone, to help pay off the debt, that too, in finite time. Along the transition, every generation faces less pollution, consumes more and is happier than if life had continued in the BAU world.
\end{abstract}

JEL-Codes: O440, Q560, H500.

Keywords: pollution, abatement, debt, environmental policy, Pareto criterion.

Torben M. Andersen*

Department of Economics and Business

Aarhus University

Fuglesangs Allé 4

Denmark - 8210 Aarhus V

tandersen@econ.au.dk

Joydeep Bhattacharya

Department of Economics

Iowa State University

USA - Ames IA 50011-1070

joydeep@iastate.edu
Pan Liu

Business School

Beijing Normal University

China - Beijing, 100875

liupan.bnu@gmail.com

*corresponding author

This Version: August 10, 2016 


\section{Introduction}

For centuries, mankind struggled with fundamental, existential issues such as food, shelter, survival; concerns about global warming and climate change hardly occupied anyone's attention and that was fine. Climatologists tell us that, before 1750, atmospheric concentrations of $\mathrm{CO}_{2}, \mathrm{CH}_{4}$, and $\mathrm{N}_{2} \mathrm{O}-$ three important long-lived greenhouse gases - were quite low. ${ }^{1}$ The Industrial Revolution changed all that. Economic growth, stuck for a millennium at around $0.5 \%$ per year, doubled to $1 \%$ or higher in Western Europe and later in the Americas. Along with increased prosperity came deforestation (to make way for agriculture) and the burning of fossil fuels (to supply the energy needs of growing economies). Atmospheric concentration of $\mathrm{CO}_{2}$ started increasing; current levels are $35 \%$ higher than what they were in 1850. The U.S. Department of Energy estimates, if nothing is done, $\mathrm{CO}_{2}$ concentrations could reach $900 \mathrm{ppm}$ by the year $2100 .^{2}$ Not a day goes by when climate scientists, economists, and politicians don't raise alarm over the expected dire consequences of inaction. ${ }^{3}$ Today climate change and global warming are viewed by many as top-level existential threats, much in the same way food, shelter, and survival concerns occupied the minds of our distant ancestors.

Unlike these other existential concerns, climate change is an externality - the Stern Review (2007) calls it the greatest market failure and largest externality in history. What is more, both the externality and the measures needed to address it are, necessarily, intergenerational in nature. After all, greenhouse gases are long-lived and their effects linger, long after they appear. Similarly, costly measures adopted today may generate benefits far into the future, well beyond the lifespan of the generations funding them. As such, any response towards combating climate change will require strong political action across generations. By the same token, however, any policy response will likely create intergenerational winners and losers and, in turn, raise thorny questions about intergenerational equity and its trade-off with efficiency. Pearson (2011) phrases it bluntly: "Should we sacrifice our use of cheap fossil fuel energy today so that generations yet unborn, who presumably will be richer than we are, can avoid adjusting to a warmer world?" Do we owe the future a clean planet? Even if we could agree that the answer to the previous question is yes, how should the near-term costs of clean-up be allocated across generations in a fair and efficient manner? For if it is not perceived to be fair, why would different generations participate in this cross-generational initiative? There are other concerns of a more practical nature. Specifically, "there is no political institution or mechanism through which the present generation can securely compensate [...future] generations for the consequences of global warming [...and symmetrically,] there is no obvious way for future generations [...] to compensate us for our sacrifices if we take expensive greenhouse abatement measures today." (Pearson, 2011; pp. 23) Is it possible to navigate our way around these concerns?

The by-now vast literature on Integrated Assessment Models (IAMs) has taken up aspects of these

\footnotetext{
${ }^{1}$ Before 1750, concentrations of $\mathrm{CO}_{2}$ and $\mathrm{CH}_{4}$ were below $280 \mathrm{ppm}$ and $790 \mathrm{ppb}$, respectively. These days, concentrations of $\mathrm{CO}_{2}$ are about $390 \mathrm{ppm}$ and $\mathrm{CH}_{4}$ levels exceed 1,770 ppb. Climatologists document that these numbers are "much higher than at any time during the last 650,000 years." Climate models suggest that only $5 \%$ of the total "extra" $\mathrm{CO}_{2}$ in the atmosphere - the $\mathrm{CO}_{2}$ that wouldn't be there if humans didn't create it - date back to pre 1850 .

${ }^{2}$ The IPCC reports that such increases in concentrations of greenhouse gases could cause global temperatures to rise substantially, even $4-6{ }^{\circ} \mathrm{C}$ or higher.

${ }^{3}$ The list of negative consequences is long and includes substantial sea-level rises, sharp decline in agricultural output, coastal erosion, demise of fish stocks, rise in the frequency of severe weather events, and massive ecosystem upheavals.
} 
overarching themes by uniting the science and economics of climate change via the damage function, a way of identifying the impacts of climate change and attributing monetary damages to them. Their goal, in many instances, is to maximize a global welfare criterion within the confines of an infinitelylived-agent, Ramsey-style model and the control variable is an abatement policy. The point is to solve for optimal paths for consumption, investment, and other variables while devoting enough resources to keeping the environment clean. Intergenerational conflict of the type discussed above is a mere sideshow in the one-agent, one-world scenario that IAMs study.

In this paper, we are conceptually motivated by the same sort of big questions that occupy the IAMs but our goal is far more modest: it is to write down a simple, analytically tractable (and therefore, stylized) model that captures the essence of the intergenerational conflict discussed above. ${ }^{4}$ Specifically, we study a small open, overlapping-generations economy in which laissez faire - the business-as-usual world (henceforth, "BAU") - is associated with declining consumption, declining welfare and worsening of the environment over generations. A government contemplates policy action aimed at correcting the underlying intergenerational externality by cleaning up the environment. Allowing for the fact that heattrapping gases such as carbon dioxide stay on for generations, benefits from the government's clean-up effort would take time to ramp up. Understandably, such a policy would create winners and losers, across cohorts. The standard response to these inter-generational equity concerns would be to postulate a social welfare function, a weighted function of the welfare of current and future generations, the likely losers and winners respectively. Depending on the weights chosen - a matter of considerable importance as discussed in the Stern Review (2007) - policy action may be justified if it maximizes the generationally-aggregated social welfare function even if it requires some generations to sacrifice for others. We refocus the issue. Along with several recent papers - Bovenberg and Heijdra (2002), Hoel et al. (2015), von Below et al. (2015), and others - we sidestep the contentious issue of assigning weights to generations and directly ask, can policy action be rationalized even after imposing the Pareto criterion, the restriction that no generation subsequent to policy action be made worse off than if business as usual had continued?

Why might we think such a line of questioning may yield answers? Standard welfare economics, recently emphasized by Foley (2007) and Heal (2009), suggests that in the presence of a huge uninternalized externality such as climate change, the business-as-usual scenario cannot be Pareto efficient and hence action to correct the externality must, in principle, offer a Pareto improvement: "the gains must outweigh the costs so that the gainers could compensate the losers and still gain. We can all come out ahead - whether we actually do is a matter of institutional design." (Heal, 2009) This remark from Heal (2009) captures the essence of our endeavor. To begin with, we employ insights from overlappinggeneration models of deficit financing - see Bovenberg and Heijdra (1998) - to address Pearson's (2011) concern about there being "no obvious way" by which generations can share clean-up costs: we allow for inter-generational compensation for investments in environment-friendly policies via debt financing. ${ }^{5}$ By insisting that such policies meet the generational Pareto criterion, we are in effect arguing that Pearson's other concern - lack of a political institution - is not that critical: after all, it seems natural to

\footnotetext{
${ }^{4}$ Our goal is not to produce a reasonably accurate model of climate-change economics nor is it to study specific policies suggested as ways to combat climate change.

${ }^{5}$ As Sachs (2014) puts it, "[t]his is an option too rarely discussed in the current debate".
} 
think that policies that satisfy the Pareto criterion are less likely to be blocked as they make their way through modern democratic processes. What makes our analysis especially challenging is the fact that the very act of compensating current generations releases its own dynamics. For sure, investments in environment-friendly policies via debt financing allow future generations to reap gains, but they also have to participate, via tax payments and additional debt purchase, in the servicing of the outstanding debt. Debt will be growing at the gross rate of interest (assumed to exceed unity) which means it is by no means trivial whether the downstream gains from a better environment can cover the aforediscussed compensation (including interest) and prevent the debt from exploding. There is the added complication that the tax instrument we study is distortionary: it affects incentives to produce, with feedback effects on both the budget and the environment and other variables influencing welfare. In sum, one major contribution of this paper lies in the demonstration of the possibility that Pareto improvements over BAU are possible and that the associated path of debt does not misbehave.

There is another important dimension in which we advance the literature. As Karp and Rezai (2014a) argues, a convergent conclusion from the literature emanating from the Stern Review (2007) and the IAMs - summarized in Heal (2009) - is that current generations must sacrifice consumption in order to combat climate change. ${ }^{67}$ This conclusion is often blamed as the reason why climate negotiations between countries have proven to be a non-starter. ${ }^{8}$ We take on the challenge of studying policies that not only satisfy the generational Pareto criterion in utility terms, but also ensure that no generation has to sacrifice consumption along the way. ${ }^{9}$ Our results connect up with the broader literature on sustainability - Neumayer (2007), Heal (2009) - that recognizes substitutability between a loss to environmental capital (due to global warming) and gains to incomes/ consumption and argues for the need to maintain at least a minimum critical level of the former. In a way, requiring that consumption not decline ties our hands substantially; it precludes the possibility of exploiting the substitutability of the environment and consumption to leave generations as happy as in the BAU.

The literature on the economics of inter-generational equity and efficiency concerns in environmental models is vast. Below, we summarize some of the papers that are closest in spirit to the current endeavor. An early contribution that led the way in terms of the search for Pareto-improving policies is Gerlagh and Keyzer (2001) who study a productive, non-renewable natural resource with amenity value and show that handing over property rights over that resource to an intergenerational trust fund that entitles every

\footnotetext{
${ }^{6}$ Kolbert (2008) profiles the goals and aspirations of a Swiss organization, the 2,000-Watt Society, which pushes for human beings to lead a life using less than two-thousand-watts of energy in a day. Evidently, the average Swiss uses about 5,000 watts and bringing this down to 2,000 would require "a significant reduction in every realm": as Kolbert (2008) puts it, "a person who continued to travel and use electricity at current rates would consume two thousand watts without having anywhere to live or work, or anything to eat."

${ }^{7}$ Nordhaus (2007) argues that assumptions in the Stern Review (2007) concerning a "low discount factor" amplifies the harmful impacts of climate change in the distant future and "rationalizes deep cuts in emissions, and indeed in all consumption, today." Rezai (2010) argues this need to cut consumption is an artifact of the constraining assumption made in IAMs that, in spite of knowing about the dangers of climate change, agents in the BAU, invest nothing in mitigation, a constrained-optimal equilibrium. This automatically implies current generations would "attain lower consumption and utility levels if they started investing in mitigation".

8 "The American way of life is not up for negotiation" - the classic U.S. position outlined by the senior President George Bush at 1992 Earth Summit in Rio de Janeiro.

${ }^{9}$ That something like this may be possible has been discussed, informally, in Foley (2007).
} 
generation to the same income claim as in the zero extraction policy can yield a Pareto improvement. ${ }^{10}$ Of course, for the initial generation to want to create the fund requires them to care about future generations. An important contribution involving intergenerational borrowing is Bovenberg and Heijdra (1998). In their setup, distant and near generations differ in their reliance on capital income (which translates to non-environmental welfare) versus environmental utility. Taxes on pollution are akin to a tax on capital and benefit distant generations - they enjoy a better environment - but hurt them because they inherit a smaller stock of physical capital. Debt, as in our paper, can be used to allow all generations to share in the efficiency gains of environmental policy, in some cases in a Pareto-improving way. ${ }^{11}$ The assumption that pollution hurts utility directly but does not affect production makes our results non-comparable; additionally, only marginal policy changes relative to the BAU are considered which means they can sidestep issues relating to long-run behavior of debt paths. ${ }^{12}$

Karp and Rezai (2014a, b) focus on the "conflict between different types of agents alive when the [mitigation] policy is first implemented". They depart from the usual one-sector OG model and allow for two sectors with an endogenously-evolving relative price between the sectors. They rely on an idea, reminiscent of Poutvaara (2004), that if investments in pollution mitigation by the current young generate increases in future asset values, then the current old - the owners of said assets - can compensate the young from those capitalized benefits leaving everyone better off, just as Heal (2009) argued would be possible. Conceptually, the novelty of their paper rests on the fact that tax-induced increases in asset prices allow market-intermediated, Pareto-improving policies even when the government cannot use bonds to redistribute across generations. ${ }^{13}$ Dao et al. (2015) study an intergenerational social compact between generations in which the young invest some of their labor income in mitigation activities in return for a subsidy to their old-age capital income paid for by the next young generation. The compact terms are such that participation in it generates a Pareto improvement compared to non-participation. They also consider compact terms that are self-sustaining, meaning any incentive to default on the contractual terms are eliminated. In an important recent contribution, von Below et al. (2015) revisit the Poutvaara (2004) and Karp and Rezai (2014a) strategy of resolving the conflict between the young and the old at the point the mitigation policy is implemented. In their setup, the old and young suffer losses in rental and wage income when energy use (which is polluting) is curtailed but the old can be offered a compensatory pension by the young in lieu of the future benefit the latter get from a better environment. The added novelty comes from the fact that the benefit from a cleaner environment accrues not just to

\footnotetext{
${ }^{10}$ Rasmussen (2003) is an early example of a paper using a calibrated OG model to study environmental taxation in a model where environmental quality is held fixed. Leach (2009) is similar in spirit but stays away studying tax or debt policies.

${ }^{11}$ Our work is part of an important literature that studies the consequences of environmental policies on environmental quality, growth and welfare (Howarth and Norgaard 1992; John and Pecchenino 1994; Jouvet et al. 2000; Gutierrez 2008; Goenka et al. 2012; Dao and Davila 2014; Wang et al. 2015). In many of these papers, environmental quality enters preferences directly. Their primary purpose is to study the role of government for eliminating the dynamic inefficiency in OG economies with environmental externalities. These papers focus on tax-financed mitigation policies and do not allow for debt financing. Intergenerational equity concerns or the search for Pareto-improving policies is not their focus. Fodha and Seegmuller (2014) do allow for debt financing but stay away from studying welfare issues along the transition.

${ }^{12} \mathrm{~A}$ salient feature of our paper is that, unlike much of the literature, our analysis handles ambitious abatement policies not just those locally around zero.

${ }^{13}$ Several of the results in Karp and Rezai $(2014 \mathrm{a}, \mathrm{b})$ hold locally near the zero tax rate while the general flavor of our results holds more widely.
} 
the current young in the future, but to all future generations; if the future beneficiaries can be co-opted into the deal between the current young and old, then far more ambitious environmental policies can be attempted without hurting any generation. Their focus, however, is not on the dynamics of the path of pensions/debt, whether they explode, nor are they seeking policies that always improve upon consumption in the BAU.

The rest of the paper is organized as follows. Section 2 describes the model small open economy with endogenous labor-leisure choice and the business as usual environment, and exposes the inefficiency arising from the environment externality. Section 3 studies a constant environmental policy under an intergenerational Pareto criterion and the associated implementation hurdles for the tractable case of quasi-linear preferences. It also analyzes debt dynamics under the Pareto criterion and studies several extensions. Section 4 considers an extension to a case with physical capital and endogenous factor prices, while Section 5 concludes. Proofs of results, some extra derivations, and some details on parameter choices are contained in the appendices.

\section{The model economy: BAU}

\subsection{Preliminaries}

To help fix ideas and generate analytical insights with manageable dynamics in both the stock of pollution and debt, we start off by studying a model in which labor is the only input and postpone introducing capital (and hence, endogenous interest rates along with capital dynamics) until Section 4 . We consider a one-good, small, open economy inhabited by two period-lived generations of agents and an infinitely-lived policymaker. At each date $t+j=0,1,2, \ldots$ a unit mass of identical agents is born. The BAU economy is indexed by $t$, and the policy is implemented from $j=0$. Agents are called "young" ("old") in the first (second) period of life. Agents are endowed with labor when young and nothing when old. The young also have access to a production technology $(F)$ that uses labor $(L)$ as the only input to produce the single, consumption good. We assume $F(L)$ has standard properties, $F_{L}(\cdot)>0, F_{L L}(\cdot)<0$ with the implication that $\frac{F(\cdot)}{L}>F_{L}(\cdot)$. All agents have complete access to perfect international capital markets and can save at a fixed, gross return $R$.

Pollution is generated as a by-product of productive activities. Let the stock of pollutants at the start of $t+j$ be denoted by $S_{t+j}$. Then, the stock of pollution at the start of $t+j+1$ is described by

$$
\text { (1) } S_{t+j+1}=(1-\epsilon) S_{t+j}+G\left(L_{t+j}\right), S_{0}>0 \text { given }
$$

where $\epsilon \in(0,1)$ is a constant that determines the speed with which pollution levels return to zero in the absence of any fresh emissions. Notice how eq. (1) captures the idea that changes to the environment can be very long-lived, spread across many cohorts. Since labor is the only input, we think of it as the polluting input as well: we posit that use of input $L_{t+j}$ generates emissions of amount $G\left(L_{t+j}\right)$ where $G(0)=0$ and $G_{L}(\cdot)>0$. Emissions can increase more (less) rapidly than input use if $G$ is assumed to be convex (concave) - see Heutel (2012). Pollution is an unintended by-product of productive activity by 
firms and no firm-level disposal of this by-product is possible. (Murty et al., 2012)

As is standard, pollution reduces the production of output as captured by a "damage function", $H(S)$, where $H(0)=1$, and $H_{S}(S)<0$ for $S>0$. Some of the analytics in the study of debt dynamics below will be conducted with a linear approximation

$$
H(S)=1-\rho S ; \rho>0 \text { and } \rho \approx 0
$$

which satisfies $H(0)=1$ and $H_{S}(S)=-\rho<0$. Net output (denoted by $y$ ) in period $t+j$ is given by

$$
y\left(S_{t+j}, L_{t+j}\right)=H\left(S_{t+j}\right) F\left(L_{t+j}\right),
$$

where it is seen that $y_{S}<0, y_{L}>0$ and $y_{S L}<0$. Pollution reduces net output (since $\left.H_{S}(S)<0\right)$ that is available for consumption. ${ }^{14}$ Also, while the marginal product of labor is positive, it declines with pollution: $H(S)$ acts as an adverse productivity "shock". Young agents produce at $t+j$ taking $S_{t+j}$ as given and $H\left(S_{t+j}\right)$ captures the damage to their output caused by this level of pollution. The point is, $S_{t+j}$ was created by the productive actions of their ancestors who did not internalize the downstream "damage"; after all, agents are not altruistic and changes in the environment have no direct effect on them.

We assume agents born in period $t+j$ care about old-age consumption $\left(c_{t+j+1}\right)$ and the disutility from young-age labor supply $\left(L_{t+j}\right)$. The utility function for generation $t+j$ is given by $U_{t+j} \equiv u\left(c_{t+j+1}\right)-$ $v\left(L_{t+j}\right)$ where $u(\cdot)$ and $v(\cdot)$ satisfies standard properties, $u_{c}>0, u_{c c} \leq 0, v_{L}>0$ and $v_{L L} \geq 0$. In much of what we do below, we assume an iso-elastic form for $u$ :

$$
u\left(c_{t+j+1}\right)=\frac{\left(c_{t+j+1}\right)^{1-\sigma}}{1-\sigma} ; \sigma \geq 0
$$

It is apparent that the relevant Arrow-Pratt measure is $\frac{-c U_{c c}}{U_{c}}=\sigma$. For future use, the special case of $\sigma=0$ will be referred to as "quasi-linear utility". Also notice $S$ (or more generally, environmental quality) does not enter agents' utility directly. Importantly, there is no altruism on the part of agents. ${ }^{15}$

\subsection{Discussion of modeling assumptions}

The model setup is necessarily barebones, designed to generate clean qualitative insights taking advantage of a lot of analytical tractability. Unlike John and Pecennino (1994), we do not embed environmental quality in the utility function, although we have explored that alternative. In their setting, pollution is a by-product of consumption, and pollution hurts utility directly; therefore, welfare can be improved via

\footnotetext{
${ }^{14}$ The Stern Review (2007) uses 5\% of GDP as the lower bound for the cost of climate change under the BAU scenario. Burke et. al (2015) show that overall economic productivity is nonlinear in temperature for all countries, rich or poor, with productivity falling sharply at temperatures higher than $13 \mathrm{C}$, and that the relationship is true for both agricultural and non-agricultural activity. Dell et. al (2012) finds strong growth effects but only for poor countries.

${ }^{15}$ We disallow altruism on the part of agents not because we think people don't care about the welfare of their progeny but because we wish to make a case for environmental action even if they didn't. Allowing altruism would also introduce private transfers from parents to children some of which may be crowded out by the government's debt policy.
} 
major cuts in consumption - we have set our goals to deliver welfare improvements without requiring consumption sacrifices. Not including environmental quality in the utility function also has another advantage. It allows us to sidestep issues relating to the substitutability between environmental and consumption goods, for as Neumeyer (2007) and others have argued, if the substitutability is low, then it may be that "no consumption growth, however high, can compensate" for the damage to the environment - after all, as Heal (2009) points out, "certain ecosystem services or products, such as water and food, are essential to survival and cannot be replaced by produced goods".

The assumption of a single input, labor, is obviously limiting but also keeps the analysis manageable. Studying a closed economy along with capital as an additional input, possibly the dirty input, would add another state variable, bring in interest rate effects, and clutter the dynamics considerably. (Such complications are studied using numerical methods in Section 4 below.) As will become clear, our focus is largely on the issue of implementation of environmental policies under an intergenerational Pareto criterion. Adding capital does not fundamentally alter our understanding of that issue.

\subsection{Agent's problem}

Agents are atomistic producers who use their production technology to produce output of amount $H\left(S_{t+j}\right) F\left(L_{t+j}\right)$. The primary decision of the agent is his choice of labor input. For future use, we introduce a $\operatorname{tax} \tau_{t+j}$ on labor. (The tax and its use is discussed in Section 3 below. For now, simply treat $\tau$ as a parameter.) Since agents do not consume when young, they save their entire aftertax, young-age income - $\left[H\left(S_{t+j}\right) F\left(L_{t+j}\right)-\tau_{t+j} L_{t+j}\right]$ - at the world interest rate, $R \geq 1$. They take $R, S_{t+j}$, and $\tau_{t+j}$ as given, and choose $L_{t+j}$ to maximize their utility subject to the budget constraint $c_{t+j+1}=R\left[H\left(S_{t+j}\right) F\left(L_{t+j}\right)-\tau_{t+j} L_{t+j}\right]$. The first order condition (assuming an interior solution ${ }^{16}$ ) is given by

$$
U_{L}=u_{c}(\cdot) R\left[H\left(S_{t+j}\right) F_{L}\left(L_{t+j}\right)-\tau_{t+j}\right]-v_{L}\left(L_{t+j}\right)=0
$$

It is easy to check that $U_{L L}<0$, implying the second order condition is satisfied. Eq. (4) implicitly defines an optimal labor supply function, $L_{t+j}=L\left(S_{t+j}, \tau_{t+j}\right)$. In the BAU, the corresponding labor supply function is given by $L_{t+j}^{B A U}=L\left(S_{t+j}^{B A U}\right)$.

In this general form, lifetime indirect utility $\tilde{U}$ equals

$$
\tilde{U}_{t+j}\left(S_{t+j}, \tau_{t+j}\right) \equiv u(\underbrace{R\left[H\left(S_{t+j}\right) F\left(L_{t+j}\left(S_{t+j}, \tau_{t+j}\right)\right)-\tau_{t+j} L_{t+j}\left(S_{t+j}, \tau_{t+j}\right)\right]}_{c_{t+j+1}})-v\left(L_{t+j}\left(S_{t+j}, \tau_{t+j}\right)\right)
$$

\footnotetext{
${ }^{16}$ If we assume $\lim _{c \rightarrow 0} u_{c}(c)=+\infty$, then we must have $L_{t+j}>0$.
} 
and under BAU, it is given by

(6) $\tilde{U}_{t+j}^{B A U}\left(S_{t+j}^{B A U}\right) \equiv u(\underbrace{R\left[H\left(S_{t+j}^{B A U}\right) F\left(L\left(S_{t+j}^{B A U}\right)\right)\right]}_{c_{t+j+1}^{B A U}})-v\left(L\left(S_{t+j}^{B A U}\right)\right)$.

We start by asking, how do agents' labor supply respond if the stock of pollution is higher?

Lemma 1 (a) In general, the signs of the comparative static labor supply responses, $\frac{\partial L_{t+j}}{\partial S_{t+j}}$ and $\frac{\partial L_{t+j}}{\partial \tau_{t+j}}$, are ambiguous. For (3), if $\sigma \leq 1, \frac{\partial L_{t+j}}{\partial S_{t+j}}<0$ and $\frac{\partial L_{t+j}}{\partial \tau_{t+j}}<0$.

(b) In the BAU, for all $\sigma>0$, we have

$$
\operatorname{sign} \frac{d L\left(S_{t+j}^{B A U}\right)}{d S_{t+j}^{B A U}}=\operatorname{sign}\left(\frac{-c_{t+j+1}^{B A U} u_{c c}(\cdot)}{u_{c}(\cdot)}-1\right)=\operatorname{sign}(\sigma-1) .
$$

The expressions for $\frac{\partial L_{t+j}}{\partial S_{t+j}}$ and $\frac{\partial L_{t+j}}{\partial \tau_{t+j}}$ outside of the BAU as well as the proof of (7) are in Appendix A. In the BAU, an increase in the stock of pollution reduces the marginal product of labor (which acts as a tax on labor supply) causing agents to want to substitute into leisure. However, there is a countervailing effect: as the environment worsens, net output (income) decreases inducing a wealth effect and incentivizing agents to want to supply more labor. The net effect is ambiguous and, as in the textbook models of labor supply, the net effect depends on risk aversion parameter. What happens to consumption?

\section{Lemma 2}

$$
\text { (a) } \frac{\partial c_{t+j+1}}{\partial S_{t+j}}<0, \quad \text { (b) } \frac{\partial c_{t+j+1}}{\partial \tau_{t+j}}<0 .
$$

The proof of Lemma 2 is in Appendix B. As the environment worsens, net output (income) decreases, shrinking the consumption possibilities of the agent. What happens to the welfare of agents?

\section{Lemma 3}

$$
\text { (a) } \frac{\partial \tilde{U}_{t+j}\left(S_{t+j}, \tau_{t+j}\right)}{\partial S_{t+j}}<0, \quad \text { (b) } \frac{\partial \tilde{U}_{t+j}\left(S_{t+j}, \tau_{t+j}\right)}{\partial \tau_{t+j}}<0
$$

The proof of Lemma 3 is in Appendix C. Agents' utility depends on their consumption and leisure. The effect of pollution on their labor supply (leisure) is washed out by the envelope theorem. What remains is the indirect effect of pollution on the output they produce - via the damage function - which goes in a negative direction. A worsening environment hurts the welfare of every generation. The effect of a higher tax on the labor input - the income, substitution effects - are washed out by the envelope theorem; what remains is the direct effect on after-tax income which reduces consumption. 


\subsection{Dynamics and steady state: BAU}

We close our discussion by asking, how does environmental quality evolve along the transition therein? Using eq. (1), it follows that the dynamics of pollution in the BAU is described by the first-order, (possibly) non-linear difference equation

(8) $\quad S_{t+j+1}^{B A U}=(1-\epsilon) S_{t+j}^{B A U}+G\left(L\left(S_{t+j}^{B A U}\right)\right)$

where, recall $\epsilon \in(0,1)$ and $G_{L}(\cdot)>0$. A non-trivial steady state in the BAU, denoted by $S_{B A U}^{*}$, is a fixed point of

(9) $S_{B A U}^{*}=\frac{G\left(L_{B A U}^{*}\right)}{\epsilon}$ where $L_{B A U}^{*} \equiv L\left(S_{B A U}^{*}\right)$.

Existence and uniqueness issues are dealt with using standard techniques. ${ }^{17}$ Similarly, imposing parametric restrictions such that

(10) $0<\left.\frac{d S_{t+j+1}^{B A U}}{d S_{t+j}^{B A U}}\right|_{S_{B A U}^{*}}<1 \Longleftrightarrow 0<1-\epsilon+\left.G_{L}\left(L\left(S_{B A U}^{*}\right)\right) \frac{d L\left(S_{t+j}^{B A U}\right)}{d S_{t+j}^{B A U}}\right|_{S_{B A U}^{*}}<1$

holds ensures local stability of $S_{B A U}^{*}$. If, in addition, we assume $S_{0}<S_{B A U}^{*}$ and "near" $S_{B A U}^{*}$, then it is apparent that the stock of pollution in the BAU is increasing and converging to $S_{B A U}^{*}$ in the long run.

\subsection{Inefficiency}

Intuitively, agents do not take into account how their own production decisions impact pollution which, in turn, affects the production decisions of their offspring. To see this more formally, we take a short detour; for now, write out the agent's and planner's problem in steady state. An agent takes $S$ as given to solve

$$
\begin{gathered}
\max _{L} U^{P} \equiv u(c)-v(L) \\
\text { s.t. } c=R H(S) F(L)
\end{gathered}
$$

The first order condition to Problem $(\mathrm{P})$ is $u_{c}(c) R H(S) F_{L}(L)-v_{L}(L)=0$ which, combined with $\epsilon S=G(L)-$ see (eq. (9)) yields

$$
u_{c}\left(R H\left(\frac{G\left(L^{P}\right)}{\epsilon}\right) F\left(L^{P}\right)\right) R H\left(\frac{G\left(L^{P}\right)}{\epsilon}\right) F_{L}\left(L^{P}\right)-v_{L}\left(L^{P}\right) \equiv 0
$$

\footnotetext{
${ }^{17}$ Define $J(S) \equiv G(L(S))-\epsilon S$. Then, it follows $J(0)=G(L(0))>0$ and $\lim _{S \rightarrow+\infty} J(S)=-\infty$ if $G$ has a finite upper bound. If $\sigma \leq 1$, then $L_{S} \leq 0$, so $J_{S}(S)=G_{L}(\cdot) L_{S}(S)-\epsilon<0$ in which case $S_{B A U}^{*}$ is unique.
} 
where $L^{P}$ is the solution to the individual's problem. ${ }^{18}$ Now consider the problem of a social planner who, in steady state, solves

$$
\begin{gathered}
\max _{L} U^{S P} \equiv u(c)-v(L) \\
\text { s.t. } c=R H(S) F(L), \epsilon S=G(L)
\end{gathered}
$$

incorporating the effect of labor supply on the environment. Denote the planner's solution by $L^{S P}$. Then,

$$
\frac{d U^{S P}}{d L}=u_{c}\left(R H(\cdot) F\left(L^{S P}\right)\right) R[\underbrace{H_{S}(.) \frac{G_{L}\left(L^{S P}\right)}{\epsilon} F\left(L^{S P}\right)}+H\left(\frac{G\left(L^{S P}\right)}{\epsilon}\right) F_{L}\left(L^{S P}\right)]-v_{L}\left(L^{S P}\right) \equiv 0 .
$$

For $L^{S P}$ to be well-defined, assume $\frac{d^{2} U^{S P}}{d L^{2}}<0$ holds. (Even though $\frac{d^{2} U^{P}}{d L^{2}}<0$ obtains, it does not follow that $\frac{d^{2} U^{S P}}{d L^{2}}<0$ holds, precisely because of the externality.) Notice, the underscored term arises because the planner takes into account the effect of his choice of $L$ on $S$ which, in turn, affects $H(S)$. This intuition is easily understood in steady state but holds more generally.

Proposition 1 In steady state, the private agent oversupplies labor (which translates into a worse environment) relative to the social planner, i.e., $L^{P}>L^{S P} \Leftrightarrow S^{P}>S^{S P}$.

The proof of Proposition 1 is in Appendix D.

\subsection{A portrait of the BAU}

In the regime without any sort of governmental involvement, the BAU world, polluting emissions are a by-product of production using the (dirty) input, labor. Starting from a low initial level of pollution, $S_{0}$, under the conditions spelt out in (10), the stock of pollution continues to rise and approaches a higher level, $S_{B A U}^{*}$, in the long run. This implies a steady, unrelenting decline in the quality of the environment. Along such a path of environmental degradation, it follows from Lemma 2 that consumption declines as well. In some utility specifications, labor supply rises along this transition, which, together with the consumption decline, serves to hurt every generation. (Figure 1)
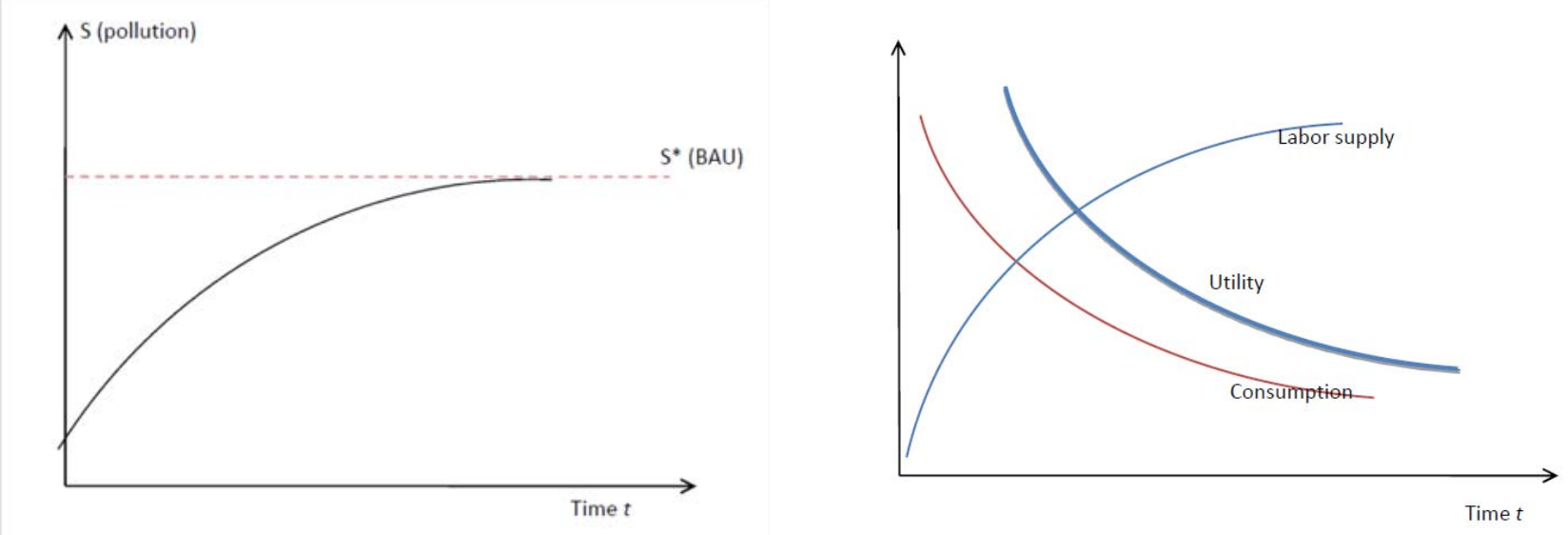

Figure 1. A portrait of the BAU, $\sigma>1$

\footnotetext{
${ }^{18}$ As discussed earlier, $\frac{d^{2} U^{P}}{d L^{2}}<0$ holds and so $L^{P}$ is well defined.
} 
Every generation pollutes and leaves a worse environment for its progeny than what it received from its parents. The worsening environmental quality hurts the children but parents - the people whose actions generated the pollution - do not care (since they are not altruistic). The big question for us is, can the government initiate a pollution-reduction policy that leaves every generation, post policy, no worse off, possibly better off, compared to their life in the BAU?

\section{$3 \quad$ Pareto-improving environmental policy}

The government wishes to implement a pollution-abatement policy designed to reduce pollution and improve environmental quality. We posit that the government announces at $j=0$ and commits to abating a fraction $\mu_{t+j}$ of the total emissions in period $t+j(j \geq 0)$, at a cost $\mathcal{A}\left(\mu_{t+j}\right)$ where

$$
\mathcal{A}\left(\mu_{t+j}\right)=\Lambda\left(\mu_{t+j}\right) G\left(L_{t+j}^{\mu}\right)
$$

The superscript $\mu$ reminds us that the variable in question is in the policy regime and $L_{t+j}^{\mu}$ solves (4). We assume $\Lambda(0)=\Lambda_{\mu}(0)=0, \Lambda_{\mu}>0, \Lambda_{\mu \mu}>0$ for $\mu>0$ : the abatement cost is 0 and minimum in the $\mathrm{BAU}$, and it is increasing and convex for positive levels of abatement. These assumptions imply that $\frac{\Lambda(\mu)}{\mu}$ is increasing in $\mu$. Under such a policy, total emissions in period $t+j$ is given by $\left(1-\mu_{t+j}\right) G\left(L_{t+j}^{\mu}\right)$ and the transition equation for the stock of pollution is given by

$$
S_{t+j+1}^{\mu}=(1-\epsilon) S_{t+j}^{\mu}+\left(1-\mu_{t+j}\right) G\left(L_{t+j}^{\mu}\right)
$$

\subsection{Government finances and debt policy}

In our world, the government is entrusted with the task of reducing the level of pollution in the economy. The government's pollution abatement efforts may start at any date, taking as given the level of pollution under BAU, $S_{t}^{B A U}$. Pollution abatement is costly. At any date, there are two modes of financing abatement expenses, either by taxation $\left(\tau_{t+j}\right)$ or by public borrowing on the international capital market at rate $R$ (with associated debt and tax dynamics which we return to below). ${ }^{19}$

A few definitions and notation descriptions are in order. Let $B_{t+j}$ denote the stock of one-period government debt at the end of period $t+j$; assume $B_{t-1}=0$ (that is, there is no outstanding debt in the BAU). Also, let $M_{t+j}$ denote the primary (i.e., non-interest) budget balance in $t+j$, the difference between tax revenue and primary expenditure (abatement cost). Then,

$$
M_{t+j}=\tau_{t+j} L_{t+j}^{\mu}-\Lambda\left(\mu_{t+j}\right) G\left(L_{t+j}^{\mu}\right)
$$

\footnotetext{
${ }^{19}$ We keep the analysis tractable by abstracting from the effects of enviromental taxes on the tax bases of other forms of taxation and the use of environmental taxes to fund non-environmental items on the government budget. For a more general treatment of this issue, see Barrage (2015).
} 
Finally, define $\mathcal{T}_{t+j}$ as the total budget balance, that is the primary balance plus interest payments. Then,

$$
\mathcal{T}_{t+j}=\tau_{t+j} L_{t+j}^{\mu}-\left[\Lambda\left(\mu_{t+j}\right) G\left(L_{t+j}^{\mu}\right)+(R-1) B_{t+j-1}\right]=M_{t+j}-(R-1) B_{t+j-1} .
$$

If $\mathcal{T}_{t+j}>0$, we say there is a government budget surplus; a negative balance is called a government budget deficit. Debt service is defined as the sum of principal repayments, $B_{t+j-1}$ (these are one-period bonds) and interest payments, $(R-1) B_{t+j-1}$. Fresh debt at $t+j, B_{t+j}$, must cover debt service on previous debt and any primary budget shortfalls, i.e., $B_{t+j}=R B_{t+j-1}-M_{t+j}$ from where it follows that change in the stock of bonds satisfies $B_{t+j}-B_{t+j-1}=-\mathcal{T}_{t+j}$.

Using the definitions above, write

$$
B_{t+j+1}-B_{t+j}=R\left(B_{t+j}-B_{t+j-1}\right)-\left(M_{t+j+1}-M_{t+j}\right)
$$

Suppose $M_{t+j+1}-M_{t+j}<0 \forall j \geq 0$ i.e., the primary budget balance deteriorates over time. Then, if $B_{t}>0, B_{t+j}-B_{t+j-1}>0 \forall j>0$ meaning debt levels increase at each date. Since $R>1$, debt levels along such a trajectory would explode rendering the policy fiscally unsustainable. Therefore, it becomes imperative the government can raise enough in tax revenue to prevent this from happening. A necessary condition for debt paths to be sustainable is that $M$ turns positive at some date and $M_{t+j+1}-M_{t+j}>0$ at some other date as well.

For future use, define the "debt turning point" as the first date, say $t+k$, for which the current debt level is below its immediate predecessor: $B_{t+k}<B_{t+k-1}$. It follows $M_{t+k}>(R-1) B_{t+k-1}$ holds only when the government has raised enough revenue to cover both its abatement expenses and interest payment, can it start to pay down the debt. The relevance of the debt turning point is this. Suppose a debt turning point is reached at $t+k$ implying the first term on the r.h.s of eq. (15) is negative: $\left(B_{t+k}-B_{t+k-1}\right)<0$. At that date, $M_{t+k}$ is positive, and if $M_{t+j+1}>M_{t+j} \forall j>k$, the second term on the r.h.s of eq. (15), $-\left(M_{t+j+1}-M_{t+j}\right)$, is also negative and together with the negative first term would imply $B_{t+j+1}<B_{t+j} \forall j \geq k$. In other words, once $M$ is positive and is rising over time (i.e., the gap between tax revenue and abatement expenses is positive and rising), then, debt levels once they fall - the debt turning point is reached - continue to fall forever after. Indeed, since it is assumed $R>1$, the debt level will reach zero in finite time. At that point, the country is debt free; if it so wishes, it can continue to raise taxes to pay for pollution abatement and any primary surplus may be lent to world markets or rebated to taxpayers. Also, it is not important for our analysis that debt vanishes; it could be set to approach a positive constant level as well. We stay away from taking a stand on any of these issues and do not study the dynamics in the economy once debt has been paid off.

\subsection{Implementation hurdles and the Pareto criterion}

It seems possible that government intervention via pollution abatement may generate welfare gains downstream relative to life in the BAU. After all, lower pollution levels in the future will, ceteris paribus, boost output and consumption. But these welfare improvements may take a while to appear since pollution abatement is a slow process. Does this mean some initial generations will have to sacrifice for the benefit 
of the future ones? Could it be possible for society to reap the distant gains of government intervention all the while ensuring no generation is harmed along the way?

Answers to these questions are not trivial. The inaugural generation does not benefit from the pollution reduction - at the point the policy is introduced, the pollution level and hence their labor supply is predetermined at BAU levels, and therefore the government must incur a debt to start things off. Higher taxes keep future debt levels low but push the burden on to current generations; likewise, lower taxes today raise the debt level, pushing the burden on to future generations, and raising the likelihood of placing debt on an exploding path. Future generations benefit from a better environment and those welfare gains can be taxed without hurting them. The question is, is this tax revenue sufficient to prevent the debt level from exploding? Does the answer to this question constrain how ambitious the abatement policy can be? An additional challenge lies ahead. Can welfare improvements be delivered by the policy without necessitating cuts in consumption along the way?

Below, we study an environment-tax policy $\left\{\mu_{t+j}=\mu, \tau_{t+j}, B_{t+j} ; j \geq 0\right\}$ that is inaugurated in period $t(j=0)$ of the BAU. The government's policy affects the start-of-period stock of pollution starting at $j=1$. This implies the inaugural generation $j=0$ is unaffected by the policy - their production, and hence, emissions, are predetermined from the BAU. It follows that under the Pareto criterion, they are not taxed. Consequently, the initial primary balance is $M_{t}=-\Lambda(\mu) G\left(L_{t}^{B A U}\right)<0$ and the initial debt needed to cover the abatement expense is positive. Thereafter, for $j>0$, the primary deficit evolves as $M_{t+j}=\tau_{t+j} L_{t+j}^{\mu}-\Lambda(\mu) G\left(L_{t+j}^{\mu}\right)$ and the stock of bonds as $B_{t+j}=R B_{t+j-1}-M_{t+j}$. The law of motion for pollution is given by $S_{t+j+1}^{\mu}=(1-\epsilon) S_{t+j}^{\mu}+(1-\mu) G\left(L\left(S_{t+j}^{\mu}, \tau_{t+j}\right)\right)$.

Our next order of business is to compute the path of taxes, $\tau_{t+j}$. Apropos our discussion above, we posit $\tau_{t+j}$ is chosen to satisfy the intergenerational Pareto criterion for $j>0$ :

$$
\tilde{U}_{t+j}^{\mu}\left(c_{t+j+1}\left(S_{t+j}^{\mu}, \tau_{t+j}\right), L_{t+j}\left(S_{t+j}^{\mu}, \tau_{t+j}\right)\right) \geq \tilde{U}_{t+j}^{B A U}\left(c_{t+j+1}\left(S_{t+j}^{B A U}\right), L_{t+j}\left(S_{t+j}^{B A U}\right)\right),
$$

where the l.h.s of (16), indirect utility under the government's environment-tax policy, is given by

$$
\tilde{U}_{t+j}^{\mu}\left(c_{t+j+1}^{\mu}, L_{t+j}^{\mu}\right)=U(\underbrace{R\left[H\left(S_{t+j}^{\mu}\right) F\left(L\left(S_{t+j}^{\mu}, \tau_{t+j}\right)\right)-\tau_{t+j} L\left(S_{t+j}^{\mu}, \tau_{t+j}\right)\right]}_{c_{t+j+1}^{\mu}}, L\left(S_{t+j}^{\mu}, \tau_{t+j}\right))
$$

and the r.h.s of (16) is the counterfactual, what indirect utility would have been had the BAU world persisted. Also note, since the inaugural generation is not taxed $\left(\tau_{t}=0\right)$ and all abatement at $j=0$ is financed via debt, it is clear the inaugural generation enjoys the same utility as they would had the BAU continued.

Implementability set for $\mu$ An abatement policy, $\mu$, is implementable under the Pareto criterion if the associated tax rates $\left\{\tau_{t+j}\right\}$ satisfy (16) and the associated path of debt, satisfying (13)-(15) is non-exploding. The set of such $\mu$ is defined as the implementability set for $\mu$, denoted $\Omega$.

Moving forward, our goal is to characterize the ${ }_{14}$ ath of taxes $\tau_{t+j}$ satisfying (16) and to prove $\Omega$, 
the implementability set for $\mu$, is non-empty. We also wish to provide an exact analysis of the dynamics of pollution under such a path of taxes and ascertain whether consumption is rising or falling along the transition.

\subsection{Pareto-improving environmental policies under quasi-linear utility}

With these goals in mind, we present a very special but tractable case of quasi-linear utility: $\sigma=0$ (quasi-linear in consumption). More general specifications will be taken up in numerical examples below. In this section, we also assume the economy is already in the BAU steady state when the policy is first implemented, i.e., $S_{t}^{B A U}=S_{B A U}^{*} \cdot{ }^{20}$

In practice, it is impossible to simply solve the non-linear inequality (16) for $\tau_{t+j}$ and use it to compute a path of Pareto-improving taxes. A convenient strategy is to compute a path of taxes, call it $\widehat{\tau}_{t+j}$, such that one of the arguments of $\tilde{U}_{t+j}^{\mu}$, labor supply, is the same in the policy regime as in the BAU. Specifically, $\widehat{\tau}_{t+j}$ is the path of taxes that equates labor supply in the policy regime with that in the BAU - i.e., $L_{t+j}^{\mu}=L_{B A U}^{*}$ where $L_{B A U}^{*}$ is defined in (9). In Appendix E, we show that for quasi-linear utility, i.e., for $\sigma=0$,

$$
\widehat{\tau}_{t+j}=\left[H\left(S_{t+j}^{\mu}\right)-H\left(S_{B A U}^{*}\right)\right] F_{L}\left(L_{B A U}^{*}\right)
$$

Using $\frac{F(.)}{L}>F_{L}($.$) , the same appendix also shows (see (30)) that c_{t+j+1}^{\mu}>c_{t+j+1}^{B A U}$ implying for the path of taxes $\widehat{\tau}_{t+j}$, all agents (from generation $t+1$ on) are strictly better off under the policy than they would have in the BAU. For now, consider an arbitrary $\mu_{t+j}=\mu$ (not necessarily one in $\Omega$ ) starting at the BAU steady state - we hold off on the associated debt dynamics as well.

Lemma 4 In the special case of quasi-linear utility, an environmental-fiscal policy package with an arbitrary $\mu_{t+j}=\mu$ starting at the BAU steady state, satisfying

$$
\tau_{t+j}=\widehat{\tau}_{t+j}=\left[H\left(S_{t+j}^{\mu}\right)-H\left(S_{B A U}^{*}\right)\right] F_{L}\left(L_{B A U}^{*}\right) ; j \geq 0
$$

makes the utility of all generations (from generation $t+1$ on) strictly higher than if the BAU had persisted. Under this package, the labor supply is the same pre and post policy while consumption is strictly higher.

The following corollary argues that the result in the previous lemma can actually be extended to include all $\sigma<1$, not just $\sigma=0$.

Corollary 1 If $\sigma<1$, for an environmental-fiscal policy package with an arbitrary $\mu_{t+j}=\mu$ starting at the BAU steady state, there exists a path of taxes $\widehat{\tau}_{t}=0$ and $0<\widehat{\tau}_{t+j}<\left[H\left(S_{t+j}^{\mu}\right)-H\left(S_{B A U}^{*}\right)\right] \frac{F\left(L_{B A U}^{*}\right)}{L_{B A U}^{*}}$, $\forall j>0$ such that $\tau_{t+j}=\widehat{\tau}_{t+j}(j \geq 0)$ gives all generations (from generation $t+1$ on) strictly higher utility than if the BAU had persisted. Under this package, the labor supply is the same pre and post policy while consumption is strictly higher.

In passing, note that the condition on $\sigma$ is a sufficient condition for the existence of such packages.

\footnotetext{
${ }^{20}$ Our methodology allows for more generality, that is, we can accommodate a setting in which the policy is inaugurated at any arbitrary point along the BAU transition. This last point is explored in numerical examples below. 


\subsubsection{Dynamics of pollution and taxes}

Since, by construction, the labor supplies are the same pre and post policy, $L_{t+j}^{\mu}=L_{B A U}^{*}$, the evolution equation for pollution can be written as

$$
S_{t+j+1}^{\mu}=(1-\epsilon) S_{t+j}^{\mu}+(1-\mu) G\left(L_{B A U}^{*}\right)
$$

The dynamics of pollution (and everything else) becomes a lot more tractable since the emissions in the policy economy are given by $(1-\mu) G\left(L_{B A U}^{*}\right)$ which is predetermined. After a bit of routine manipulation, it can be shown that

$$
\begin{aligned}
S_{t+j+1}^{\mu} & =(1-\epsilon)^{j+1} S_{t}^{\mu}+\frac{1-(1-\epsilon)^{j+1}}{\epsilon}(1-\mu) G\left(L_{B A U}^{*}\right) \\
& =\left[(1-\epsilon)^{j+1} \mu+(1-\mu)\right] S_{B A U}^{*} ; j \geq 0 .
\end{aligned}
$$

Clearly, $S_{t+j}^{\mu}$ is declining relative to $S_{B A U}^{*}$ over time. Therefore $\widehat{\tau}_{t+j}=\left[H\left(S_{t+j}^{\mu}\right)-H\left(S_{B A U}^{*}\right)\right] F_{L}\left(L_{B A U}^{*}\right)$ is rising because $H$ is increasing over time. These ideas are collected in the following proposition.

Proposition 2 The case studied in Lemma 4 is associated with a declining path of pollution relative to the BAU steady-state level. The path of taxes is increasing, however.

Next, we turn to the all-important question, if the path of taxes is defined by $\widehat{\tau}_{t+j}$, what is the associated path for the public debt? Most importantly, does satisfying the Pareto criterion render the path explosive? In other words, is the implementability set associated with the $\mu$ defined in Lemma 4 non-empty?

\subsubsection{Path of debt}

As discussed in Section 3.1, using $L_{t+j}^{\mu}=L_{B A U}^{*}$, the primary budget is given by

$$
M_{t+j}=\widehat{\tau}_{t+j} L_{t+j}^{\mu}-\Lambda(\mu) G\left(L_{t+j}^{\mu}\right)=\left[H\left(S_{t+j}^{\mu}\right)-H\left(S_{B A U}^{*}\right)\right] F_{L}\left(L_{B A U}^{*}\right) L_{B A U}^{*}-\Lambda(\mu) G\left(L_{B A U}^{*}\right)
$$

implying the primary budget evolves as

$$
M_{t+j+1}-M_{t+j}=\left[H\left(S_{t+j+1}^{\mu}\right)-H\left(S_{t+j}^{\mu}\right)\right] F_{L}\left(L_{B A U}^{*}\right) L_{B A U}^{*}>0
$$

since $S^{\mu}$ has been established to be declining over time. Knowing $M_{t+j+1}-M_{t+j}>0$ for all $j$, it follows from the evolution equation for debt $B_{t+j+1}-B_{t+j}=R\left(B_{t+j}-B_{t+j-1}\right)-\left(M_{t+j+1}-M_{t+j}\right)$ that if at some date $k, B_{t+k}-B_{t+k-1}<0$, then $B_{t+j+1}-B_{t+j}<0, \forall j \geq k$. Debt levels, once they fall, continue to fall forever after. And because $R>1$, the debt reaches 0 in finite time.

As discussed in Section 3.1, there are three critical dates of interest. First, when does $M_{t+j}$ turn positive? The aforediscussed process of debt decline cannot start until a date when $M_{t+j}$ turns positive, that is the government starts to run up a surplus of tax revenue over its abatement expenditures (after all, only then can it turn its attention to debt servicing). Second, when does $B_{t+j+1}-B_{t+j}<0$ first happen? And third, when does $B_{t+j} \rightarrow 0$ ? We take these up in turn. For what we present below, we 
use the linear approximation for the damage function as in (2) for tractability's sake - this convenience is abandoned in numerical examples below.

\subsubsection{The first date when $M_{t+j}$ turns positive}

Recall that the initial primary deficit, $M_{t}=-\Lambda(\mu) G\left(L_{B A U}^{*}\right)<0$ and hence the initial debt needed to cover the abatement expense is positive. Thereafter the primary budget balance evolves in a manner described by (20). Also recall that a necessary condition for the path of debt to decline is that $M_{t+j}$ turns positive. Using (20) and (2), it is possible to write

$$
M_{t+j}=\epsilon \mu S_{B A U}^{*}\left(\frac{\rho F_{L}\left(L_{B A U}^{*}\right) L_{B A U}^{*}}{\epsilon}\left(1-(1-\epsilon)^{j}\right)-\frac{\Lambda(\mu)}{\mu}\right)
$$

Suppose the first date when $M_{t+j}$ turns positive is $j=k_{1}$.

Lemma 5 Suppose $\mu \in\left(0, \bar{\mu}_{1}\right)$ where $1-\frac{\epsilon}{\rho F_{L}\left(L_{B A U}^{*}\right) L_{B A U}^{*}} \frac{\Lambda\left(\bar{\mu}_{1}\right)}{\bar{\mu}_{1}} \equiv 0$. Then,

$$
k_{1}=\frac{\ln \left(1-\frac{\epsilon}{\rho F_{L}\left(L_{B A U}^{*}\right) L_{B A U}^{*}} \frac{\Lambda(\mu)}{\mu}\right)}{\ln (1-\epsilon)}
$$

and hence the first date when $M_{t+j}$ turns positive is $t+\left\lceil k_{1}\right\rceil$ where $\left\lceil k_{1}\right\rceil$ is the smallest integer not less than $k_{1}$. Also, that first date rises as $\mu$ increases.

The proof of Lemma 5 is in Appendix F. Note that $M_{t+j}$ turning positive is a necessary condition for debt vanishes so $\mu$ within the range $\left(0, \bar{\mu}_{1}\right)$ are not necessarily in the implementability set $\Omega$.

\subsubsection{The first date when the debt starts to decline: the debt turning point}

The change in the level of debt between $t+j$ and $t+j+1$ is:

$$
\Delta B_{t+j+1} \equiv B_{t+j+1}-B_{t+j}=R\left(B_{t+j}-B_{t+j-1}\right)-\left(M_{t+j+1}-M_{t+j}\right)
$$

which upon repeated iteration yields

$$
\Delta B_{t+j+1}=-\sum_{i=0}^{j} R^{j-i}\left(M_{t+i+1}-M_{t+i}\right)+R^{j+1}\left(B_{t}-B_{t-1}\right)=-R^{j+1}\left(\sum_{i=0}^{j} \frac{M_{t+i+1}-M_{t+i}}{R^{i+1}}+M_{t}\right) .
$$

Using (2), it is possible to write $M_{t+i+1}-M_{t+i}=\epsilon \mu \rho S_{B A U}^{*} F_{L}\left(L_{B A U}^{*}\right) L_{B A U}^{*}(1-\epsilon)^{i}$, which leads to

$$
\Delta B_{t+j+1}=-R^{j+1} \epsilon \mu S_{B A U}^{*}\left(\frac{\rho F_{L}\left(L_{B A U}^{*}\right) L_{B A U}^{*}}{R-1+\epsilon}\left(1-\left(\frac{1-\epsilon}{R}\right)^{j+1}\right)-\frac{\Lambda(\mu)}{\mu}\right)
$$

Suppose the first date when the debt declines is $j=k_{2}$. 
Proposition 3 Suppose $\mu \in\left(0, \bar{\mu}_{2}<\bar{\mu}_{1}\right) \sqsubset \Omega$ where $1-\frac{R-1+\epsilon}{\rho F_{L}\left(L_{B A U}^{*}\right) L_{B A U}^{*}} \frac{\Lambda\left(\bar{\mu}_{2}\right)}{\bar{\mu}_{2}} \equiv 0$. Then,

$$
k_{2}=\frac{\ln \left(1-\frac{R-1+\epsilon}{\rho F_{L}\left(L_{B A U}^{*}\right) L_{B A U}^{*}} \frac{\Lambda(\mu)}{\mu}\right)}{\ln \left(\frac{1-\epsilon}{R}\right)}
$$

and hence the first date when the debt starts to decline is $t+\left\lceil k_{2}\right\rceil$ where $\left\lceil k_{2}\right\rceil$ is the smallest integer not less than $k_{2}$. Also, that first date rises as $\mu$ increases.

The proof of Proposition 3 is in Appendix G. Note, if $\mu>\bar{\mu}_{2}$, the debt keeps increasing and eventually explodes. If we want the debt to decrease right away $\left(B_{t+1}<B_{t}\right)$, we need $k_{2}<1$, which requires $\frac{\Lambda(\mu)}{\mu}<\frac{\rho F_{L}\left(L_{B A U}^{*}\right) L_{B A U}^{*}}{R}$ to hold.

\subsubsection{The first date when debt levels reach zero}

The debt in period $t+j$ (iterating $B_{t+j}=R B_{t+j-1}-M_{t+j}$ and using $B_{t-1}=0$ ) is given by

$$
B_{t+j}=-R^{j} \sum_{i=0}^{j} \frac{M_{t+i}}{R^{i}}
$$

Using (2), it is possible to write

$$
B_{t+j}=-\epsilon \mu S_{B A U}^{*} \frac{R^{j+1}-1}{R-1}\left(\frac{\rho F_{L}\left(L_{B A U}^{*}\right) L_{B A U}^{*}}{\epsilon}\left(1-\frac{R-1}{R-1+\epsilon} \frac{1-\left(\frac{1-\epsilon}{R}\right)^{j+1}}{1-\left(\frac{1}{R}\right)^{j+1}}\right)-\frac{\Lambda(\mu)}{\mu}\right) .
$$

Suppose the date at which the debt hits zero is $j=k_{3}$.

Proposition 4 Suppose $\mu \in\left(0, \bar{\mu}_{2}\right) \sqsubset \Omega$, the same range of $\mu$ that is required for the existence of the debt turning point in Proposition 3. Then, $k_{3}$ is the solution to

$$
\frac{\rho F_{L}\left(L_{B A U}^{*}\right) L_{B A U}^{*}}{\epsilon}\left(1-\frac{R-1}{R-1+\epsilon} \frac{1-\left(\frac{1-\epsilon}{R}\right)^{k_{3}+1}}{1-\left(\frac{1}{R}\right)^{k_{3}+1}}\right)=\frac{\Lambda(\mu)}{\mu}
$$

and hence the first date when debt hits zero is $t+\left\lceil k_{3}\right\rceil$ where $\left\lceil k_{3}\right\rceil$ is the smallest integer not less than $k_{3}$. Also, that first date rises as $\mu$ increases.

The proof of Proposition 4 is in Appendix H. Recall $B_{t}=\epsilon S_{B A U}^{*} \Lambda(\mu)>0$ and $B_{t+1}=-\epsilon \mu S_{B A U}^{*}(1+R)\left(\frac{\rho F_{L}\left(L_{B A U}^{*}\right) L_{B A U}^{*}}{1+R}-\frac{\Lambda(\mu)}{\mu}\right)$. If we want the debt to turn negative from the second period $\left(B_{t+1}<0\right)$, we need $\frac{\Lambda(\mu)}{\mu}<\frac{\rho F_{L}\left(L_{B A U}^{*}\right) L_{B A U}^{*}}{1+R}$ to hold. It is a subset of the range of $\mu$ which makes debt decline from the second period $\left(\frac{\Lambda(\mu)}{\mu}<\frac{\rho F_{L}\left(L_{B A U}^{*}\right) L_{B A U}^{*}}{R}\right)$.

The upshot is that the implementability set for $\mu$ is non-empty, that there exists a range of $\mu$ that the government can usher in under a intergenerational Pareto criterion that leaves every generation at least as well off, possibly better, than if the BAU world had continued. The policy economy has lower pollution and higher consumption as well. 


\subsection{An illustration of debt dynamics and some robustness checks}

In this section, we study the robustness of some of our aforediscussed results to some alternative formulations. First and foremost, we wish to demonstrate that the general tenor of our results go through when $\sigma>1$. Second, we check if the policy can be inaugurated at any point in the BAU transition, not necessarily at the steady state. Third, we had, for tractability's sake assumed an affine damage function in the computation of the debt dynamics; here, we relax that restriction as well. The big robustness question, the one about extending the analysis to a closed economy with endogenous factor returns, is postponed to Section 4 below.

The goal here is not a full-blown calibration exercise but rather to paint a picture of the Paretoimproving transition with broad brushstrokes to see if environmental policy can improve matters and the make sure the associated debt paths behave. The following functional forms are used: ${ }^{21}$

$$
\begin{aligned}
& \text { utility: } U_{t+j}\left(c_{t+j+1}, L_{t+j}\right)=\frac{c_{t+j+1}^{1-\sigma}}{1-\sigma}-\beta \frac{L_{t+j}^{1-\gamma}}{1-\gamma} ; \sigma \geq 0, \beta>0, \gamma<0 . \\
& \text { production: } F\left(L_{t+j}\right)=A L_{t+j}^{\alpha} ; A>0,0<\alpha<1 . \\
& \text { damage: } H\left(S_{t+j}\right)=\frac{1}{1+\rho S_{t+j}^{2}} ; \rho>0 . \\
& \text { abatement } \operatorname{cost}: \Lambda(\mu)=\lambda \mu^{\phi} ; \lambda>0, \phi>1 . \\
& \text { emission : } G\left(L_{t+j}\right)=\delta L_{t+j}^{\theta} ; \delta>0, \theta>0 .
\end{aligned}
$$

Implementation under the Pareto criterion depends critically on debt dynamics, as explained above. To illustrate some key insights, Figure 2 reports the debt paths for various scenarios. First, implementation depends on the level of abatement $(\mu)$. As illustrated in Figure 2a, low levels of abatement does not require much debt and the turning point is reached quickly, whereas more ambitious policies cause more debt and it takes longer to reach the turning point. There is a critical level of abatement above which implementation is not possible. When implementation is possible, there is scope to provide gains upfront $^{22}$ as illustrated in Figure $2 \mathrm{~b}$, where $\eta=0$ corresponds to unchanged utility relative to the BAU steady-state (the Pareto neutral criterion) and $\eta=0.5 \%$ allow all cohorts to have a utility gain of $0.5 \%$ relative to the BAU steady state. As expected, front-loading of the gains imply higher debt and a later turning point, i.e., implementation becomes more difficult. Finally, if the policy is implemented before the BAU has reached steady-state, implementation becomes easier (Figure 2c) showing that delay of abatement is costly.

\footnotetext{
${ }^{21}$ The parameters are chosen as follows: $\sigma=2, \beta=0.4, \gamma=-2, A=280, \alpha=0.64, \rho=4 \times 10^{-7}, \lambda=0.039, \phi=1.5$, $\delta=1000, \theta=0.9, R=2$ and $\epsilon=0.126$.

${ }^{22}$ As explained earlier, the way we've set things up, the generation born at the inaugural date cannot benefit from this environmental policy, unless the government borrows to makes transfers to them (which we disallow). The inaugural generations' utility is held at the BAU level; all others are made strictly better off.
} 
Figure 2: Debt dynamics: Abatement policies, utility criterion and initial situation

(a) Debt to GDP ratio (B/y):

Different levels of abatement $(n=0)$

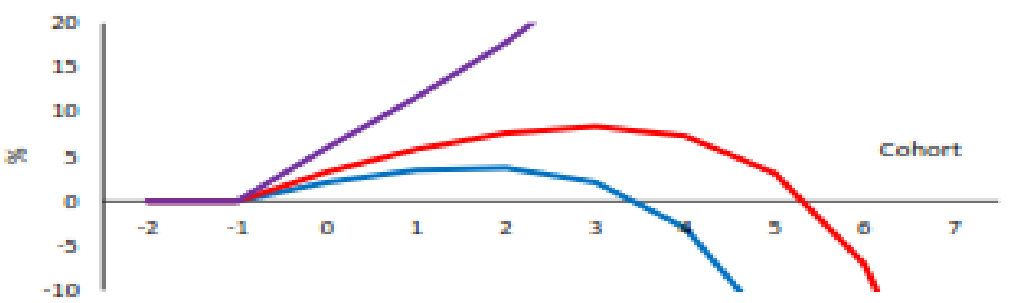

$\longrightarrow \mu=0.15-\mu=0.2-\mu=0.3$

(b) Debt to GDP ratio:

$n=0$ and $n=0.5 \%(\mu=0.15)$

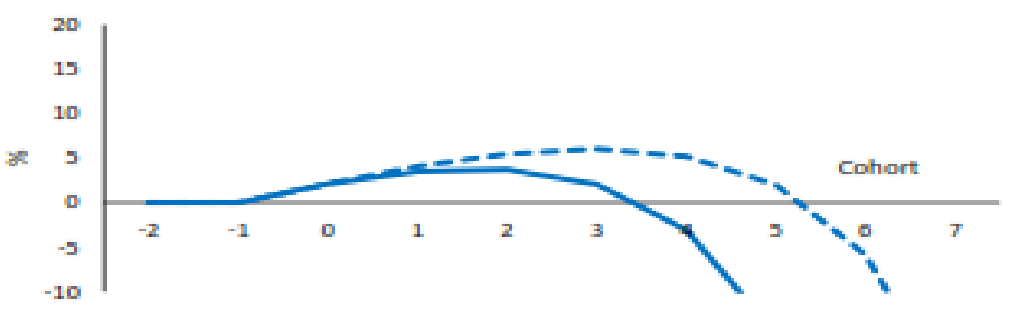

$n=0--n=0.93$

(c) Debt to GDP ratio:

Importance of initial situation $(\mu=0.15)$

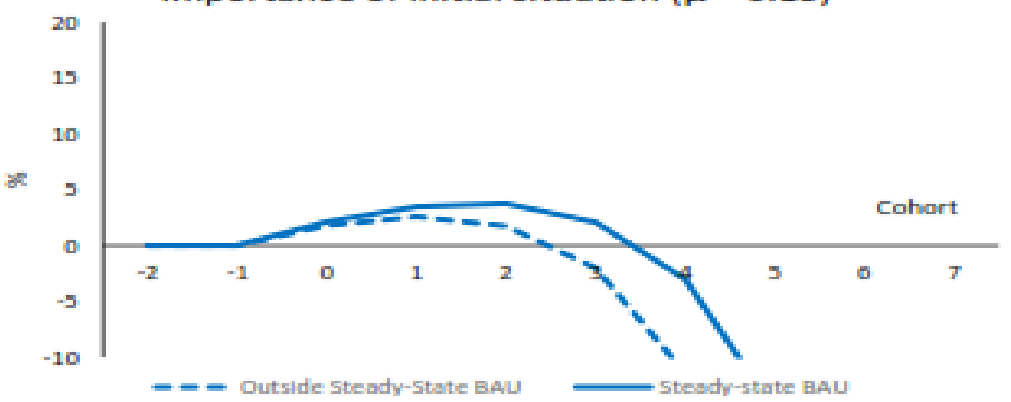

Note: In all simulations the initial situation is the BAU steady state. In (c), the initial situation outside BAU steady state we set $S_{j=0}=0.85 \times S_{B A U}^{*}$.

\section{An extension: closed economy with endogenous factor prices}

How does our previous discussion change if the assumption of a small open economy is abandoned in favour of a closed economy (with neoclassical production)? With neoclassical production, factor prices, especially interest rates, are endogenous and the effects of policy choices at the initial date will, via its general equilibrium effects on endogenous variables such as saving (and hence the capital stock, and factor returns), will linger. It is apparent that debt will, initially, crowd out private saving thereby reducing 
the capital stock and help bring down production-related emissions. This would cause the wage rate to decrease and the interest rate to increase. The dynamics of debt becomes immensely complicated since it gets coupled with the dynamics of both the endogenously-evolving capital stock and the pollution stock. Whether these general equilibrium effects ease the implementation hurdles at future dates is not at all clear. Below, we briefly sketch this more general model and study it numerically to check if the general tenor of our results derived earlier is preserved.

\subsection{The model economy}

We consider an otherwise standard, closed-economy Diamond (1965) model and augment it to include pollution. ${ }^{23}$ Agents work when young and are retired when old. There is no population growth, and the population size is normalized to 1 . Firms use capital and labor to produce the single, consumption good using a standard CRS technology $F\left(K_{t+j}, L_{t+j}\right)$ where $K$ is capital. Emissions, in this case, are generated from the use of capital. At time $t(j=0)$, the government starts to implement an environmental policy so as to abate a fraction $\mu>0$ of the fresh emissions generated in each period. To finance the abatement-related expenses, the government may impose a $\operatorname{tax} \tau^{K}$ on firms for the use of the dirty input, capital. If needed, the government can also issue "environmental bonds". All trade is conducted in perfectly competitive markets and there are no market imperfections.

For firms, the net output in period $t+j$ equals

$$
y_{t+j}=H\left(S_{t+j}\right) F\left(K_{t+j}, L_{t+j}\right)=H\left(S_{t+j}\right) A K_{t+j}^{\alpha} L_{t+j}^{1-\alpha},
$$

where $A>0$ and $0<\alpha<1$. At $t+j$, firms take pollution stock $S_{t+j}$, interest rate $R_{t+j}$, wage rate $w_{t+j}$ and tax rate $\tau_{t+j}^{K}$ as given and solve

$$
\max _{K_{t+j}^{d}, L_{t+j}^{d}} H\left(S_{t+j}\right) F\left(K_{t+j}^{d}, L_{t+j}^{d}\right)-\left(R_{t+j}+\tau_{t+j}^{K}\right) K_{t+j}^{d}-w_{t+j} L_{t+j}^{d}
$$

The first order conditions read

$$
\begin{aligned}
R_{t+j}+\tau_{t+j}^{K} & =\alpha A H\left(S_{t+j}\right)\left(K_{t+j}^{d}\right)^{\alpha-1}\left(L_{t+j}^{d}\right)^{1-\alpha} \\
w_{t+j} & =(1-\alpha) A H\left(S_{t+j}\right)\left(K_{t+j}^{d}\right)^{\alpha}\left(L_{t+j}^{d}\right)^{-\alpha}
\end{aligned}
$$

Agents born in period $t+j$ care about young-age consumption $\left(c_{t+j}^{y}\right)$ and old-age consumption $\left(c_{t+j+1}^{o}\right) \cdot{ }^{24}$ Since the return on public debt is the same as return on capital, agents are indifferent between the two forms of savings. Let $s_{t+j}$ be the total savings by generation $t+j$. Agents in generation

\footnotetext{
${ }^{23}$ The basic structure is the same as that discussed above. The Diamond model with a pollution externality is a workhorse environment in the macro-environement literature - see Gutierrez (2008), Goenka et al. (2012) and Farmer and Bednar-Friedl (2010).

${ }^{24}$ We stay away from allowing an endogenous labor-leisure choice since that adds another dimension to the ensuing $3 \mathrm{D}$ dynamics without the potential for great, additional insight.
} 
$t+j$ take $w_{t+j}, R_{t+j+1}$ as given and solve

$$
\begin{aligned}
& \max _{c_{t+j}^{y}, c_{t+j+1}^{o}} U_{t+j}\left(c_{t+j}^{y}, c_{t+j+1}^{o}\right)=\frac{\left(c_{t+j}^{y}\right)^{1-\sigma}}{1-\sigma}+\beta \frac{\left(c_{t+j+1}^{o}\right)^{1-\sigma}}{1-\sigma}, \sigma>0 \\
& \text { s.t. } c_{t+j}^{y}=w_{t+j}-s_{t+j} \\
& c_{t+j+1}^{o}=R_{t+j+1} s_{t+j}
\end{aligned}
$$

from which we derive the optimal saving function, $s_{t+j}=\frac{w_{t+j}}{1+\beta^{-\frac{1}{\sigma}}\left(R_{t+j+1}\right)^{1-\frac{1}{\sigma}}}$ and then the indirect utility $\widetilde{U}_{t+j}$.

In any period $t+j$, polluting emissions are generated as a by-product of capital use, $G\left(K_{t+j}\right)$. The pollution stock evolves according to

$$
S_{t+j+1}=(1-\epsilon) S_{t+j}+(1-\mu) G\left(K_{t+j}\right)
$$

Government incurs abatement costs of amount $\mathcal{A}_{t+j}=\Lambda(\mu) G\left(K_{t+j}\right)$ in period $t+j$. The stock of debt at the end of $t+j$ equals

$$
B_{t+j}=R_{t+j} B_{t+j-1}+\mathcal{A}_{t+j}-\tau_{t+j}^{K} K_{t+j}
$$

Also, the next period's capital stock is determined by $K_{t+j+1}^{s}=s_{t+j}-B_{t+j} .{ }^{25}$

In equilibrium, $L_{t+j}^{d}=L_{t+j}^{s}=1$, and $K_{t+j}^{d}=K_{t+j}^{s}=K_{t+j}$, so factor prices are $R_{t+j}=\alpha A H\left(S_{t+j}\right) K_{t+j}^{\alpha-1}-$ $\tau_{t+j}^{K}$, and $w_{t+j}=(1-\alpha) A H\left(S_{t+j}\right) K_{t+j}^{\alpha}$ using which we derive optimal saving to be

$$
s_{t+j}=\frac{(1-\alpha) A H\left(S_{t+j}\right) K_{t+j}^{\alpha}}{1+\beta^{-\frac{1}{\sigma}}\left(\alpha A H\left(S_{t+j+1}\right) K_{t+j+1}^{\alpha-1}-\tau_{t+j+1}^{K}\right)^{1-\frac{1}{\sigma}}} .
$$

Combining the above equilibrium relationships, we derive the endogenously-evolving laws of motion for the economy. At the start of period $t+j$, the pollution stock $S_{t+j}$, the capital stock $K_{t+j}$, the public debt level $B_{t+j-1}$ and the sequence of tax rates $\left\{\tau_{t+k}^{K}\right\}_{k \geq j}$ are known - the government announces and commits to this path of taxes, which are in turn computed under the Pareto criterion. Then $\left\{K_{t+j+1}, S_{t+j+1}, B_{t+j}\right\}$ are determined by

$$
\begin{aligned}
S_{t+j+1} & =(1-\epsilon) S_{t+j}+(1-\mu) G\left(K_{t+j}\right), \\
B_{t+j} & =\left(\alpha A H\left(S_{t+j}\right) K_{t+j}^{\alpha-1}-\tau_{t+j}^{K}\right) B_{t+j-1}+\Lambda(\mu) G\left(K_{t+j}\right)-\tau_{t+j}^{K} K_{t+j}, \\
K_{t+j+1} & =\frac{(1-\alpha) A H\left(S_{t+j}\right) K_{t+j}^{\alpha}}{1+\beta^{-\frac{1}{\sigma}}\left(\alpha A H\left(S_{t+j+1}\right) K_{t+j+1}^{\alpha-1}-\tau_{t+j+1}^{K}\right)^{1-\frac{1}{\sigma}}}-B_{t+j} .
\end{aligned}
$$

What is important for our purposes is that the path of debt constrained by the Pareto criterion eventually turns around and is headed downward thereafter. For concreteness sake, we discontinue the government

\footnotetext{
${ }^{25}$ Notice, allowing debt to go negative would have the direct effect of raising the capital stock thereby hurting the environ-
} ment. 
policy once the debt has been paid off; it is not important whether the economy has reached the new steady state by then. For completeness, note that in the BAU, the dynamics are given by

$$
\begin{aligned}
& S_{t+j+1}=(1-\epsilon) S_{t+j}+G\left(K_{t+j}\right) \\
& K_{t+j+1}=\frac{(1-\alpha) A H\left(S_{t+j}\right) K_{t+j}^{\alpha}}{1+\beta^{-\frac{1}{\sigma}}\left(\alpha A H\left(S_{t+j+1}\right) K_{t+j+1}^{\alpha-1}\right)^{1-\frac{1}{\sigma}}} .
\end{aligned}
$$

The unique BAU steady state is characterized by

$$
\begin{aligned}
& \text { (26) } S=\frac{G(K)}{\epsilon}, \\
& \text { (27) } K=\frac{(1-\alpha) A H(S) K^{\alpha}}{1+\beta^{-\frac{1}{\sigma}}\left(\alpha A H(S) K^{\alpha-1}\right)^{1-\frac{1}{\sigma}}} .
\end{aligned}
$$

\subsection{Numerics}

Resorting to numerical analysis allows us to check the robustness of our theory to alternative assumptions, many of which had been made, to begin with, for analytical tractability. Our analysis below is designed to offer qualitative insight - the goal here, once again, is not to offer a disciplined calibration exercise but rather to offer a general sense of the Pareto-improving transition and see if environmental policy can improve matters and associated debt paths do not veer off. We start by assigning functional forms and parameter values that are in line with established practice in the literature. The following functional forms are used:

utility: $U_{t+j}\left(c_{t+j}^{y}, c_{t+j+1}^{o}\right)=\frac{\left(c_{t+j}^{y}\right)^{1-\sigma}}{1-\sigma}+\beta \frac{\left(c_{t+j+1}^{o}\right)^{1-\sigma}}{1-\sigma} ; \sigma>0,0<\beta<1$.

production: $F\left(L_{t+j}\right)=A K_{t+j}^{\alpha} L_{t+j}^{1-\alpha} ; A>0,0<\alpha<1$.

damage: $H\left(S_{t+j}\right)=\frac{1}{1+\rho S_{t+j}^{2}} ; \rho>0$.

abatement cost: $\Lambda(\mu)=\lambda \mu^{\phi} ; \lambda>0, \phi>1$.

emissions : $G\left(K_{t+j}\right)=\delta K_{t+j}^{\theta} ; \delta>0, \theta>0$.

The parameters of the model are chosen as follows:

\begin{tabular}{c|c|c|} 
UTILITY & PRODUCTION & ABATEMENT COST \\
\hline \hline$\sigma=2$ & $A=327$ & $\lambda=0.866$ \\
$\beta=0.7$ & $\alpha=0.36$ & $\phi=2.5$ \\
\hline EMISSION & DECAY RATE & DAMAGE \\
$\delta=1.165$ & $\epsilon=0.126$ & $\rho=4 \times 10^{-7}$ \\
$\theta=0.9$ & &
\end{tabular}

Table 1: Parameter Values

Appendix I contains a detailed discussion explaining the rationale for these parameter choices, many of which are taken from Karp and Rezai (2014b). We consider the following environmental policy: the 
government starts to abate $40 \%$ of the emissions generated in each period (hence, $\mu=0.4$ ) in a situation where the economy is in the BAU steady state. Figure 3 displays the adjustment paths for some key variables for two scenarios; one under the Pareto neutral criterion (labelled $\eta=0$ ) and one where gains are released up-front by allowing all cohorts a utility improvement of $4 \%$ relative to the BAU steady state $(\eta=4 \%)$. The specifics of the algorithm used to compute the paths is discussed in Appendix J. We show a case where the policy can be implemented, see Figure 3f, and in accordance with above, the up-front utility gains imply higher debt and a later turning point. Along the adjustment path, taxes can be increased (Figure 3e) since agents are better off, and the tax revenue is sufficient to ensure the implementation of the policy, even if some up-front utility gains are allowed. The abatement policy ensures a lower pollution stock (Figure 3a), and importantly higher output (Figure 3c) and life-time consumption (Figure 3d). ${ }^{26}$ The path for the interest rate (Figure 3b) reflects that the issuance of public debt crowds out private capital resulting in a higher interest rate. Along the adjustment path this effect is turned around alongside reductions in public debt.

\footnotetext{
${ }^{26}$ Defined as the present value of life-time consumption, i.e ${ }_{24} c_{t+j}^{L T} \equiv c_{t+j}^{y}+\frac{c_{t+j+1}^{o}}{R_{t+j+1}}$.
} 
Figure 3: Adjustment to abatement policies with endogenous factor prices

(a) Pollution stock (S)

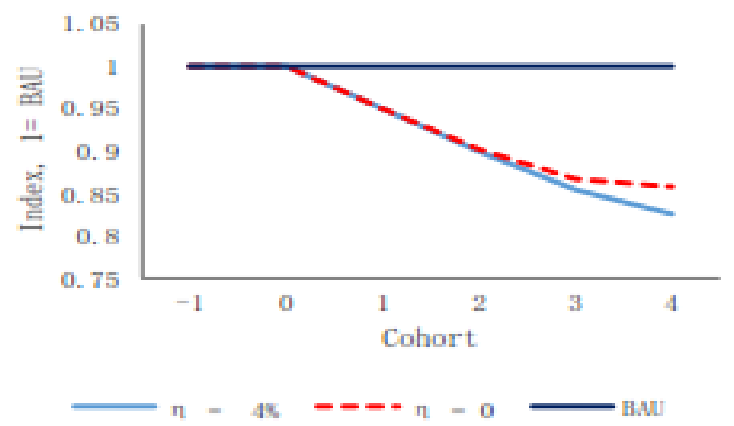

(c) Output (y)

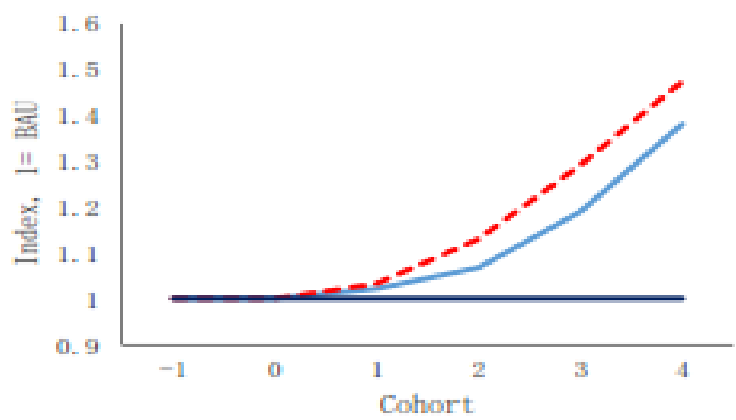

(e) $\operatorname{Tax}$ rate $(\tau)$

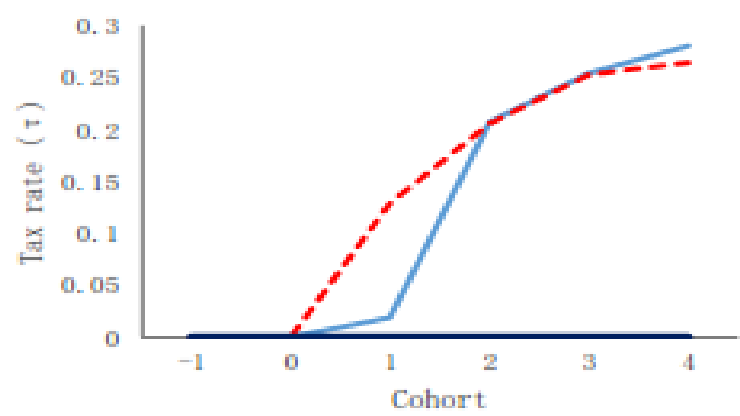

(b) Interest rate ( $\mathrm{R})$

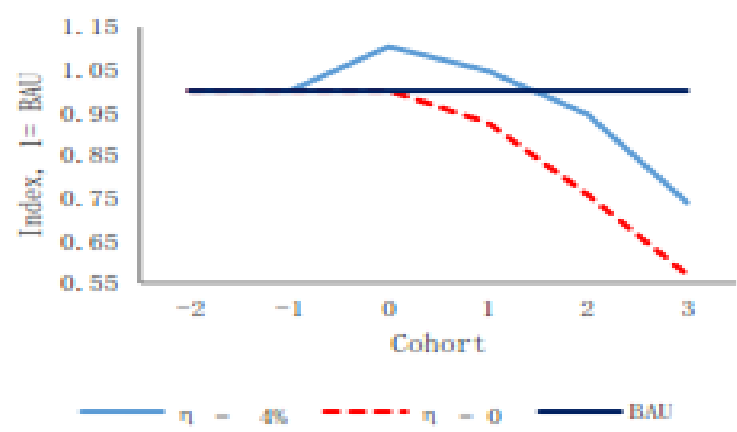

(d) Life-time consumption (cLT)

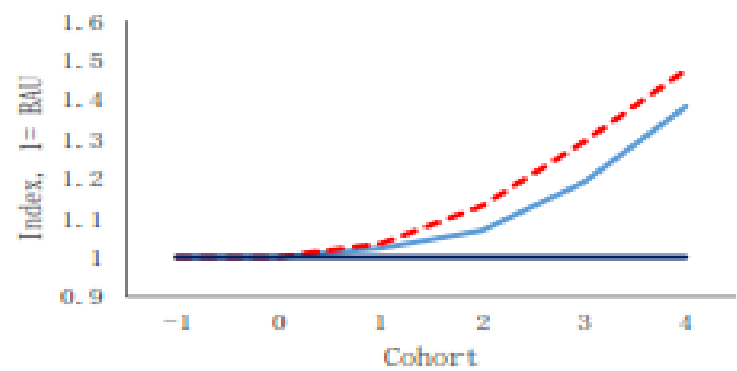

(f) Debt to GDP ratio (B/y)

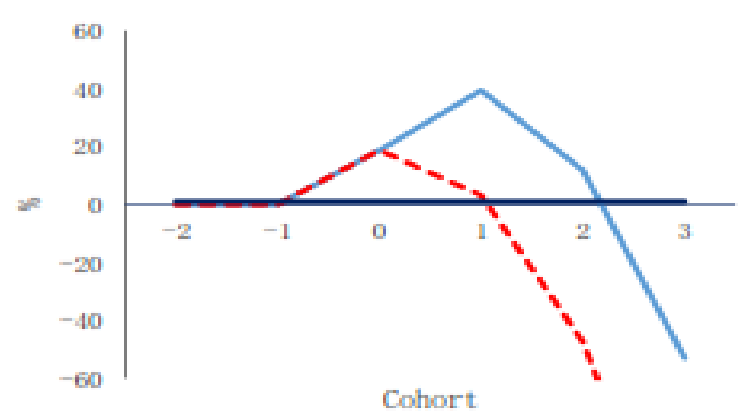

\section{Concluding remarks}

This paper studies a tractable economy populated by overlapping generations of agents facing a standard stock externality from pollution caused by productive activities. In the laissez faire equilibrium, environmental quality gets worse over time, and consumption and utility falls. The business-as-usual situation is a grim one and presents an opportunity for government intervention in the form of pollution abatement. The catch is that such policies are costly and it takes a while for the benefits to start appearing in a substantial way. The government can borrow to start the abatement and can tax some of the downstream welfare gains to help pay down the debt. The big question is, can the government usher in such an environmental policy that makes sure that no generation is hurt (indeed "all" are better off) and the 
debt is paid off in finite time? We show, the answer is in the affirmative. The new equilibrium has lower pollution levels than in the business as usual world. Along the transition, every generation is better off (at least no worse off) in utility terms and consumption is also rising.

Our analysis has also stayed away from studying alternative policies that put a direct cap on labor supply (through mandatory length of work week laws) or imposes capital controls. Also, instead of using debt, the generations could work out a corresponding path of intergenerational transfers as in von Below et al. (2015). It is our conjecture that any attempt to introduce such policies under the Pareto criterion would presumably face similar implementation hurdles as raised here.

In future work, we are exploring the quantitative margins of the paper by incorporating it into a North-South, two-country calibrated integrated assessment model of climate change. Interactions and coordination on abatement policies between the North and the South as well as a study of carbon-tax policies are interesting issues we take up in that setting. 


\section{Appendices}

\section{A Proof of Lemma 1}

From the first order condition (4), we can calculate

$$
\begin{aligned}
U_{L L} & =u_{c c}(\cdot) R^{2}\left[H\left(S_{t+j}\right) F_{L}\left(L_{t+j}\right)-\tau_{t+j}\right]^{2}+u_{c}(\cdot) R H\left(S_{t+j}\right) F_{L L}\left(L_{t+j}\right)-v_{L L}\left(L_{t+j}\right)<0, \\
U_{L S} & =u_{c c}(\cdot) R\left[H\left(S_{t+j}\right) F_{L}\left(L_{t+j}\right)-\tau_{t+j}\right] R H_{S}\left(S_{t+j}\right) F\left(L_{t+j}\right)+u_{c}(\cdot) R H_{S}\left(S_{t+j}\right) F_{L}\left(L_{t+j}\right) \\
& =u_{c}(\cdot) R H_{S}\left(S_{t+j}\right) F_{L}\left(L_{t+j}\right)[1-\underbrace{\frac{-c_{t+j+1} u_{c c}(\cdot)}{u_{c}(\cdot)}}_{=\sigma \text { for }(3)} \underbrace{\frac{H\left(S_{t+j}\right) F\left(L_{t+j}\right)-\tau_{t+j} \frac{F\left(L_{t+j}\right)}{F_{L}\left(L_{t+j}\right)}}{H\left(S_{t+j}\right) F\left(L_{t+j}\right)-\tau_{t+j} L_{t+j}}}_{<1 \text { since } \frac{F(\cdot)}{F_{L}(\cdot)}>L}],
\end{aligned}
$$

and

$$
\begin{aligned}
U_{L \tau} & =-u_{c c}(\cdot) R L_{t+j} R\left[H\left(S_{t+j}\right) F_{L}\left(L_{t+j}\right)-\tau_{t+j}\right]-u_{c}(\cdot) R \\
& =-u_{c}(\cdot) R[1-\underbrace{\frac{-c_{t+j+1} u_{c c}(\cdot)}{u_{c}(\cdot)}}_{=\sigma \text { for }(3)} \underbrace{\frac{H\left(S_{t+j}\right) F_{L}\left(L_{t+j}\right) L_{t+j}-\tau_{t+j} L_{t+j}}{H\left(S_{t+j}\right) F\left(L_{t+j}\right)-\tau_{t+j} L_{t+j}}}_{<1 \text { since } F_{L}(\cdot) L<F(\cdot)}] .
\end{aligned}
$$

It follows that $\frac{\partial L_{t+j}}{\partial S_{t+j}}=-\frac{U_{L S}}{U_{L L}}$ and $\frac{\partial L_{t+j}}{\partial \tau_{t+j}}=-\frac{U_{L \tau}}{U_{L L}}$. In general, we cannot sign $\frac{\partial L_{t+j}}{\partial S_{t+j}}$ or $\frac{\partial L_{t+j}}{\partial \tau_{t+j}}$. For (3), if $\sigma \leq 1$, we have $\frac{\partial L_{t+j}}{\partial S_{t+j}}<0$ and $\frac{\partial L_{t+j}}{\partial \tau_{t+j}}<0$.

In the BAU, $\tau=0$, and then $\frac{d L_{t+j}}{d S_{t+j}}\left(\frac{\partial L_{t+j}}{\partial S_{t+j}}\right)$ can be simplified to

$$
\left.\frac{d L_{t+j}}{d S_{t+j}}\right|_{B A U}=-\frac{u_{c}(\cdot) R H_{S}\left(S_{t+j}\right) F_{L}\left(L_{t+j}\right)\left[1-\frac{-c_{t+j+1} u_{c c}(\cdot)}{u_{c}(\cdot)}\right]}{U_{L L}} .
$$

The rest follows.

\section{B Proof of Lemma 2}

Using $c_{t+j+1}=R\left[H\left(S_{t+j}\right) F\left(L_{t+j}\left(S_{t+j}, \tau_{t+j}\right)\right)-\tau_{t+j} L_{t+j}\left(S_{t+j}, \tau_{t+j}\right)\right]$, we have

$$
\begin{aligned}
\frac{\partial c_{t+j+1}}{\partial S_{t+j}} & =R\left[H_{S}\left(S_{t+j}\right) F\left(L_{t+j}\right)+\left(H\left(S_{t+j}\right) F_{L}\left(L_{t+j}\right)-\tau_{t+j}\right) \frac{\partial L_{t+j}}{\partial S_{t+j}}\right] \\
& =R\left[H_{S}\left(S_{t+j}\right) F\left(L_{t+j}\right)-\left(H\left(S_{t+j}\right) F_{L}\left(L_{t+j}\right)-\tau_{t+j}\right) \frac{U_{L S}}{U_{L L}}\right] \\
& =R \frac{H_{S}\left(S_{t+j}\right) F\left(L_{t+j}\right) U_{L L}-\left(H\left(S_{t+j}\right) F_{L}\left(L_{t+j}\right)-\tau_{t+j}\right) U_{L S}}{U_{L L}} .
\end{aligned}
$$


Plug in the expressions for $U_{L L}$ and $U_{L S}$ (see appendix A) and we get

$$
\begin{aligned}
\frac{\partial c_{t+j+1}}{\partial S_{t+j}} & =R H_{S}(\cdot) F(\cdot) \frac{u_{c}(\cdot) R H\left(S_{t+j}\right) F_{L L}\left(L_{t+j}\right)-u_{c}(\cdot) R \frac{F_{L}\left(L_{t+j}\right)}{F\left(L_{t+j}\right)}\left(H\left(S_{t+j}\right) F_{L}\left(L_{t+j}\right)-\tau_{t+j}\right)-v_{L L}\left(L_{t+j}\right)}{U_{L L}} \\
& <0 .
\end{aligned}
$$

Similarly,

$$
\begin{aligned}
\frac{\partial c_{t+j+1}}{\partial \tau_{t+j}} & =R\left[\left(H\left(S_{t+j}\right) F_{L}\left(L_{t+j}\right)-\tau_{t+j}\right) \frac{\partial L_{t+j}}{\partial \tau_{t+j}}-L_{t+j}\right] \\
& =R\left[-\left(H\left(S_{t+j}\right) F_{L}\left(L_{t+j}\right)-\tau_{t+j}\right) \frac{U_{L \tau}}{U_{L L}}-L_{t+j}\right] \\
& =-R \frac{\left(H\left(S_{t+j}\right) F_{L}\left(L_{t+j}\right)-\tau_{t+j}\right) U_{L \tau}+L_{t+j} U_{L L}}{U_{L L}} \\
& =-R \frac{-u_{c}(\cdot) R\left(H\left(S_{t+j}\right) F_{L}\left(L_{t+j}\right)-\tau_{t+j}\right)+u_{c}(\cdot) R H\left(S_{t+j}\right) F_{L L}\left(L_{t+j}\right) L_{t+j}-v_{L L}\left(L_{t+j}\right) L_{t+j}}{U_{L L}} \\
& <0 .
\end{aligned}
$$

\section{Proof of Lemma 3}

By the envelope theorem, we have

$$
\frac{\partial \tilde{U}_{t+j}}{\partial S_{t+j}}=R U_{c}(\cdot) H_{s}(\cdot) F(\cdot)<0
$$

and

$$
\frac{\partial \tilde{U}_{t+j}}{\partial \tau_{t+j}}=-R U_{c}(\cdot) L_{t+j}<0
$$

\section{Proof of Proposition 1}

$$
\frac{d U^{S P}}{d L}=u_{c}\left(R H\left(\frac{G(L)}{\epsilon}\right) F(L)\right) R\left[H_{S}(.) \frac{G_{L}(L)}{\epsilon} F(L)+H\left(\frac{G(L)}{\epsilon}\right) F_{L}(L)\right]-v_{L}(L) .
$$

When evaluated at $L^{P}$, using the first order condition to the agent's problem, $u_{c}\left(R H\left(\frac{G\left(L^{P}\right)}{\epsilon}\right) F\left(L^{P}\right)\right) R H\left(\frac{G\left(L^{P}\right)}{\epsilon}\right) F_{L}\left(L^{P}\right)-v_{L}\left(L^{P}\right)=0$, we have

$$
\left.\frac{d U^{S P}}{d L}\right|_{L^{P}}=u_{c}\left(R H\left(\frac{G\left(L^{P}\right)}{\epsilon}\right) F\left(L^{P}\right)\right) R\left[H_{S}(.) \frac{G_{L}\left(L^{P}\right)}{\epsilon} F\left(L^{P}\right)\right]<0,
$$

implying $L^{P}>L^{S P}$. 


\section{E Path of taxes under policy-invariant labor supply}

As discussed above, the inaugural generation $t(j=0)$ is unaffected by the policy. Because of the government's abatement activity during period $t$, the start-of-period stock of pollution next period $(j=1)$ satisfies $S_{t+1}^{\mu}<S_{t+1}^{B A U}$. If the government imposes no taxes in $t+1$, then it follows from Lemma 3 that generation $t+1$ will be strictly better off, i.e., $\widetilde{U}_{t+1}\left(S_{t+1}^{\mu}, \tau_{t+1}=0\right)>\widetilde{U}_{t+1}^{B A U}\left(S_{t+1}^{B A U}\right)$. Some or all of this welfare gain may be taxed away by the government to help defray (part of) the abatement and debt service costs in that period. According to Lemma 3, once the tax is imposed, welfare will fall (relative to $\left.\widetilde{U}_{t+1}\left(S_{t+1}^{\mu}, 0\right)\right)$. Hence there exists a range for the tax rate, say $\tau_{t+1} \in\left[0, \bar{\tau}_{t+1}\right]$ such that $\widetilde{U}_{t+1}\left(S_{t+1}^{\mu}, \tau_{t+1}\right) \geq \widetilde{U}_{t+1}^{B A U}\left(S_{t+1}^{B A U}\right)$. When $\tau_{t+1}=\bar{\tau}_{t+1}, \widetilde{U}_{t+1}=\widetilde{U}_{t+1}^{B A U}$ (a Pareto-neutral choice of tax) and if $\tau_{t+1}=0$, the government leaves all the welfare gains to generation $t+1$.

For now, we set aside Pareto criterion (16) and our search for Pareto-improving taxes and instead focus on a subset of taxes, $\left\{\widehat{\tau}_{t+j}\right\}_{j=0}^{\infty}$ such that $L_{t+j}^{\mu}=L\left(S_{t+j}^{\mu}, \widehat{\tau}_{t+j}\right)=L\left(S_{t+j}^{B A U}\right)=L_{B A U}^{*} \forall j>0$. In other words, $\widehat{\tau}_{t+j}$ is chosen to keep labor supply under the government's policy the same as its level in the BAU. This helps fix the second argument of $\widetilde{U}(.,$.$) in (16). We wish to investigate what implication this$ may have for the first argument, consumption, and via this channel, dig deeper into (16). The associated debt dynamics are a separate matter which we will turn to further below.

Start with the optimality conditions for labor supply, pre and post policy, and use them to back out the necessary path of taxes using the fact $L_{t+j}^{\mu}=L\left(S_{t+j}^{B A U}\right)$. This means

BAU: $u_{c}(\underbrace{R H\left(S_{t+j}^{B A U}\right) F\left(L_{t+j}^{B A U}\right)}_{c_{t+j+1}^{B A U}}) R H\left(S_{t+j}^{B A U}\right) F_{L}\left(L_{t+j}^{B A U}\right)-v_{L}\left(L_{t+j}^{B A U}\right)=0$
policy: $u_{c}(\underbrace{R\left[H\left(S_{t+j}^{\mu}\right) F\left(L_{t+j}^{\mu}\right)-\widehat{\tau}_{t+j} L_{t+j}^{\mu}\right]}_{c_{t+j+1}^{\mu}}) R\left[H\left(S_{t+j}^{\mu}\right) F_{L}\left(L_{t+j}^{\mu}\right)-\widehat{\tau}_{t+j}\right]-v_{L}\left(L_{t+j}^{\mu}\right)=0$ with $L_{t+j}^{\mu}=L_{t+j}^{B A U}$

For (3), these equations reduce to

$$
\left(\frac{H\left(S_{t+j}^{\mu}\right)}{H\left(S_{t+j}^{B A U}\right)}-\frac{\widehat{\tau}_{t+j}}{H\left(S_{t+j}^{B A U}\right) \frac{F\left(L_{t+j}^{B A U}\right)}{L_{t+j}^{B A U}}}\right)^{\sigma}=\frac{H\left(S_{t+j}^{\mu}\right)}{H\left(S_{t+j}^{B A U}\right)}-\frac{\widehat{\tau}_{t+j}}{H\left(S_{t+j}^{B A U}\right) F_{L}\left(L_{t+j}^{B A U}\right)}
$$

For a moment, consider an example where $\frac{F\left(L_{t}\right)}{L_{t}}=F_{L}\left(L_{t}\right)$, i.e., $F\left(L_{t}\right)$ is a linear function of $L_{t}$. Then, 
for all $\sigma \neq 1,(28)$ becomes

$$
\left(\frac{H\left(S_{t+j}^{\mu}\right)}{H\left(S_{t+j}^{B A U}\right)}-\frac{\widehat{\tau}_{t+j}}{H\left(S_{t+j}^{B A U}\right) F_{L}\left(L_{t+j}^{B A U}\right)}\right)^{\sigma-1}=1 \Leftrightarrow \widehat{\tau}_{t+j}=\left[H\left(S_{t+j}^{\mu}\right)-H\left(S_{t+j}^{B A U}\right)\right] F_{L}\left(L_{t+j}^{B A U}\right)
$$

and

$$
c_{t+j+1}^{\mu}=R\left[H\left(S_{t+j}^{\mu}\right) F\left(L_{t+j}^{B A U}\right)-\widehat{\tau}_{t+j} L_{t+j}^{B A U}\right]=R H\left(S_{t+j}^{B A U}\right) F\left(L_{t+j}^{B A U}\right)=c_{t+j+1}^{B A U} .
$$

In this special case, under the tax policy, $\widehat{\tau}_{t+j}$, labor supply (by construction) and consumption are exactly the same as in the BAU. In that case, the equal utility condition (16) is satisfied and then $\widehat{\tau}_{t+j}$, for this special case, is also the path of Pareto-neutral taxes. Note, however, this does not mean pollution levels are the same pre and post policy.

More generally, $\frac{F\left(L_{t}\right)}{L_{t}}>F_{L}\left(L_{t}\right)$ holds. In this more general setting, first note, when $\sigma=1$, there does not exist $\widehat{\tau}_{t+j}>0$ satisfying (28) and therefore, labor supply pre and post policy cannot be the same. This is because with a logarithmic utility, a better environment has no direct effect on the labor supply. If the government nevertheless collects taxes anyway, labor supply would change.

If $\sigma \neq 1$, then with $\widehat{\tau}_{t+j}>0$, eq. (28) implies

$$
\left(\frac{H\left(S_{t+j}^{\mu}\right)}{H\left(S_{t+j}^{B A U}\right)}-\frac{\widehat{\tau}_{t+j}}{H\left(S_{t+j}^{B A U}\right) \frac{F\left(L_{t+j}^{B A U}\right)}{L_{t+j}^{B A U}}}\right)^{\sigma-1}<1
$$

If $\sigma<1$, then it follows from (29) that $\widehat{\tau}_{t+j}$ must satisfy $\widehat{\tau}_{t+j}<\left[H\left(S_{t+j}^{\mu}\right)-H\left(S_{t+j}^{B A U}\right)\right] \frac{F\left(L_{t+j}^{B A U}\right)}{L_{t+j}^{B A U}}$, in which case

$$
c_{t+j+1}^{\mu}=R\left[H\left(S_{t+j}^{\mu}\right) F\left(L_{t+j}^{B A U}\right)-\widehat{\tau}_{t+j} L_{t+j}^{B A U}\right]>R H\left(S_{t+j}^{B A U}\right) F\left(L_{t+j}^{B A U}\right)=c_{t+j+1}^{B A U}
$$

must hold. This means tax rates that keep labor supply unchanged pre and post policy $\left(\widehat{\tau}_{t+j}\right)$ will benefit agents in consumption terms and offer higher utility relative to what they would get in the BAU. Since $\frac{\partial \tilde{U}_{t+j}}{\partial \tau_{t+j}}<0$ (see Lemma 3), the government can raise tax rates relative to $\widehat{\tau}_{t+j}$ so as to bring utility down to the BAU level - this would be the "Pareto-neutral tax rate". Such an action would decrease labor supply relative to BAU: recall, at $\widehat{\tau}_{t+j}$, the labor supply pre and post policy are the same; also, we have established that $\frac{\partial L_{t+j}}{\partial \tau_{t+j}}<0$ if $\sigma<1$. Hence if $\sigma<1$, imposing Pareto-neutral tax rate reduces both labor supply and consumption relative to the BAU.

In general, we cannot solve $\widehat{\tau}_{t+j}$ explicitly from (28). In the special case of quasi-linear utility $(\sigma=0)$, using (28) we get $\widehat{\tau}_{t+j}=\left[H\left(S_{t+j}^{\mu}\right)-H\left(S_{t+j}^{B A U}\right)\right] F_{L}\left(L_{t+j}^{B A U}\right)$. And if the starting point is the steady state, $\widehat{\tau}_{t+j}=\left[H\left(S_{t+j}^{\mu}\right)-H\left(S_{B A U}^{*}\right)\right] F_{L}\left(L_{B A U}^{*}\right)$.

If $\sigma>1$, it follows from (29) that $\widehat{\tau}_{t+j}$ must satisfy $\widehat{\tau}_{t+j}>\left[H\left(S_{t+j}^{\mu}\right)-H\left(S_{t+j}^{B A U}\right)\right] \frac{F\left(L_{t+j}^{B A U}\right)}{L_{t+j}^{B A U}}$, in 
which case

$$
c_{t+j+1}^{\mu}=R\left[H\left(S_{t+j}^{\mu}\right) F\left(L_{t+j}^{B A U}\right)-\widehat{\tau}_{t+j} L_{t+j}^{B A U}\right]<R H\left(S_{t+j}^{B A U}\right) F\left(L_{t+j}^{B A U}\right)=c_{t+j+1}^{B A U} .
$$

So if $\sigma>1$, imposing tax rates that keep labor supply pre and post policy unchanged makes every postinaugural generation in the policy regime worse off than they would be if the BAU had continued. Since $\frac{\partial \tilde{U}_{t+j}}{\partial \tau_{t+j}}<0$, the government can reduce tax rates relative to $\widehat{\tau}_{t+j}$ so as to bring utility up to the BAU level or higher.

\section{F Proof of Lemma 5}

$$
M_{t+j}=\epsilon \mu S_{B A U}^{*}\left(\frac{\rho F_{L}\left(L_{B A U}^{*}\right) L_{B A U}^{*}}{\epsilon}\left(1-(1-\epsilon)^{j}\right)-\frac{\Lambda(\mu)}{\mu}\right) .
$$

Because $M_{t}<0$ and $M_{t+j}$ is increasing over time, to calculate the first date when it turns positive, we solve

$$
M_{t+k_{1}}=0
$$

and get (for $\mu>0$ )

$$
(1-\epsilon)^{k_{1}}=1-\frac{\epsilon}{\rho F_{L}\left(L_{B A U}^{*}\right) L_{B A U}^{*}} \frac{\Lambda(\mu)}{\mu}
$$

Only when $1-\frac{\epsilon}{\rho F_{L}\left(L_{B A U}^{*}\right) L_{B A U}^{*}} \frac{\Lambda(\mu)}{\mu}>0$ can we have a solution for $k_{1}$. Because $\frac{\Lambda(\mu)}{\mu}$ is increasing in $\mu$, this sets an upper bound for $\mu$, denoted by $\bar{\mu}_{1}$, which satisfies

$$
1-\frac{\epsilon}{\rho F_{L}\left(L_{B A U}^{*}\right) L_{B A U}^{*}} \frac{\Lambda\left(\bar{\mu}_{1}\right)}{\bar{\mu}_{1}}=0
$$

Within the range $\left(0, \bar{\mu}_{1}\right)$, we can solve

$$
k_{1}=\frac{\ln \left(1-\frac{\epsilon}{\rho F_{L}\left(L_{B}^{*}\right) L_{B}^{*}} \frac{\Lambda(\mu)}{\mu}\right)}{\ln (1-\epsilon)} .
$$

We get the first date when $M$ turns positive $\left(k^{M>0}\right)$ by rounding up (taking the ceiling of $\left.k_{1}\right): k^{M>0}=$ $t+\left\lceil k_{1}\right\rceil$. It can be easily shown that $\frac{d k_{1}}{d \mu}>0$.

\section{G Proof of Proposition 3}

$$
\Delta B_{t+j+1}=-R^{j+1} \epsilon \mu S_{B A U}^{*}\left(\frac{\rho F_{L}\left(L_{B A U}^{*}\right) L_{B A U}^{*}}{R-1+\epsilon}\left(1-\left(\frac{1-\epsilon}{R}\right)^{j+1}\right)-\frac{\Lambda(\mu)}{\mu}\right) .
$$

Recall $B_{t}=-M_{t}>0$. Because once debt begins to fall, it falls forever, to calculate the first date when 
it declines, we solve

$$
\Delta B_{t+k_{2}}=0
$$

and get (for $\mu>0$ )

$$
\left(\frac{1-\epsilon}{R}\right)^{k_{2}}=1-\frac{R-1+\epsilon}{\rho F_{L}\left(L_{B A U}^{*}\right) L_{B A U}^{*}} \frac{\Lambda(\mu)}{\mu}
$$

Only when $1-\frac{R-1+\epsilon}{\rho F_{L}\left(L_{B A U}^{*}\right) L_{B A U}^{*}} \frac{\Lambda(\mu)}{\mu}>0$ can we have a solution for $k_{2}$. Because $\frac{\Lambda(\mu)}{\mu}$ is increasing in $\mu$, this sets an upper bound for $\mu$, denoted by $\bar{\mu}_{2}$, which satisfies

$$
1-\frac{R-1+\epsilon}{\rho F_{L}\left(L_{B A U}^{*}\right) L_{B A U}^{*}} \frac{\Lambda\left(\bar{\mu}_{2}\right)}{\bar{\mu}_{2}}=0
$$

Since $R>1, \bar{\mu}_{2}<\bar{\mu}_{1}$. This is consistent with our understanding that a necessary condition for debt decline is to have a positive $M$ at an earlier date. Within the range $\left(0, \bar{\mu}_{2}\right)$, we can solve

$$
k_{2}=\frac{\ln \left(1-\frac{R-1+\epsilon}{\rho F_{L}\left(L_{B A U}^{*}\right) L_{B A U}^{*}} \frac{\Lambda(\mu)}{\mu}\right)}{\ln \left(\frac{1-\epsilon}{R}\right)}
$$

We get the first date when debt declines $\left(k^{\triangle B<0}\right)$ by rounding up (taking the ceiling of $k_{2}$ ): $k^{\Delta B<0}=$ $t+\left\lceil k_{2}\right\rceil$. It can be easily shown that $\frac{d k_{2}}{d \mu}>0$.

\section{H Proof of Proposition 4}

$$
B_{t+j}=-\epsilon \mu S_{B}^{*} \frac{R^{j+1}-1}{R-1}\left(\frac{\rho F_{L}\left(L_{B A U}^{*}\right) L_{B A U}^{*}}{\epsilon}\left(1-\frac{R-1}{R-1+\epsilon} \frac{1-\left(\frac{1-\epsilon}{R}\right)^{j+1}}{1-\left(\frac{1}{R}\right)^{j+1}}\right)-\frac{\Lambda(\mu)}{\mu}\right)
$$

Recall $B_{t}=-M_{t}>0$. To calculate the first date when debt hits zero, we solve

$$
B_{t+k_{3}}=0
$$

and get (for $\mu>0$ )

$$
\frac{\rho F_{L}\left(L_{B A U}^{*}\right) L_{B A U}^{*}}{\epsilon}\left(1-\frac{R-1}{R-1+\epsilon} \frac{1-\left(\frac{1-\epsilon}{R}\right)^{k_{3}+1}}{1-\left(\frac{1}{R}\right)^{k_{3}+1}}\right)=\frac{\Lambda(\mu)}{\mu}
$$

If we know the range of $\frac{1-\left(\frac{1-\epsilon}{R}\right)^{k_{3}+1}}{1-\left(\frac{1}{R}\right)^{k_{3}+1}}$, then using the above equation we can find the range of $\mu$ that ensures 
the existence of $k_{3}$. To proceed, define $z\left(k_{3}\right) \equiv \frac{1-\left(\frac{1-\epsilon}{R}\right)^{k_{3}+1}}{1-\left(\frac{1}{R}\right)^{k_{3}+1}}, k_{3}>0$.

$$
\begin{aligned}
\frac{d z\left(k_{3}\right)}{d k_{3}} & =\frac{-\left(\frac{1-\epsilon}{R}\right)^{k_{3}+1}\left(1-\left(\frac{1}{R}\right)^{k_{3}+1}\right) \ln \frac{1-\epsilon}{R}+\left(1-\left(\frac{1-\epsilon}{R}\right)^{k_{3}+1}\right)\left(\frac{1}{R}\right)^{k_{3}+1} \ln \frac{1}{R}}{\left(1-\left(\frac{1}{R}\right)^{k_{3}+1}\right)^{2}} \\
& =\frac{\left(1-\left(\frac{1-\epsilon}{R}\right)^{k_{3}+1}\right)\left(1-\left(\frac{1}{R}\right)^{k_{3}+1}\right)}{\left(1-\left(\frac{1}{R}\right)^{k_{3}+1}\right)^{2}}\left(\frac{\left(\frac{1}{R}\right)^{k_{3}+1} \ln \frac{1}{R}}{1-\left(\frac{1}{R}\right)^{k_{3}+1}}-\frac{\left(\frac{1-\epsilon}{R}\right)^{k_{3}+1} \ln \frac{1-\epsilon}{R}}{1-\left(\frac{1-\epsilon}{R}\right)^{k_{3}+1}}\right)
\end{aligned}
$$

Define $Q(x)=\frac{x \ln x}{1-x}$. It can be easily shown that $\frac{d Q(x)}{d x}=\frac{\ln x-x+1}{(x-1)^{2}}<0$ for $0<x<1$. For $k_{3}>0$, $0<\left(\frac{1-\epsilon}{R}\right)^{k_{3}+1}<\left(\frac{1}{R}\right)^{k_{3}+1}<1$, so

$$
\frac{\left(\frac{1}{R}\right)^{k_{3}+1} \ln \frac{1}{R}}{1-\left(\frac{1}{R}\right)^{k_{3}+1}}-\frac{\left(\frac{1-\epsilon}{R}\right)^{k_{3}+1} \ln \frac{1-\epsilon}{R}}{1-\left(\frac{1-\epsilon}{R}\right)^{k_{3}+1}}=\frac{Q\left(\left(\frac{1}{R}\right)^{k_{3}+1}\right)-Q\left(\left(\frac{1-\epsilon}{R}\right)^{k_{3}+1}\right)}{k_{3}+1}<0
$$

which implies $\frac{d z\left(k_{3}\right)}{d k_{3}}<0$ for $0<k_{3}<+\infty$. So $z\left(k_{3}\right)=\frac{1-\left(\frac{1-\epsilon}{R}\right)^{k_{3}+1}}{1-\left(\frac{1}{R}\right)^{k_{3}+1}} \in\left(1, \frac{R-1+\epsilon}{R-1}\right)$. To ensure the existence of $k_{3}$, we require

$$
\frac{\Lambda(\mu)}{\mu}<\frac{\rho F_{L}\left(L_{B A U}^{*}\right) L_{B A U}^{*}}{R-1+\epsilon},
$$

i.e., $\mu \in\left(0, \bar{\mu}_{2}\right)$, the same range of $\mu$ for the existence of a turning point. We get the first date when debt hits zero $\left(k^{B<0}\right)$ by rounding up (taking the ceiling of $\left.k_{3}\right): k^{B<0}=t+\left\lceil k_{3}\right\rceil$. Also, since $\frac{d z\left(k_{3}\right)}{d k_{3}}<0$, it can be easily shown that $\frac{d k_{3}}{d \mu}>0$.

\section{Discussion of parameter choices}

The functional forms for utility $U(\cdot)$, damage $H(\cdot)$ and corresponding parameter values $(\sigma, \beta$ and $\rho)$ and decay rate $(\epsilon)$ are in line with those used in Karp and Rezai (2014b). $\alpha$ is chosen to make capital's share of output equal to 0.36 as in Heutel (2012). $\theta=0.9$, indicating emissions a concave function of capital used in the production.

The total factor productivity $A$ and emission intensity $\delta$ are calibrated following the same way in Karp and Rezai (2014b). "We scale nominal units by $10^{9} 2010$ USD $(\$ T)$. Current capital stock, $K_{0}$, is roughly $200 \$ T$. Yearly world output is roughly $63 \$ T$, so output in one 35 -year period is $y_{0}=35 \times 63 \approx 2200 \$ T$. [...] Currently, 8.36 Gt $\mathrm{C}$ are burnt per year. This corresponds to an annual increase in atmospheric $\mathrm{CO}_{2}$ of 3.92 ppmv." (Karp and Rezai 2014b; pp. 20) So total factor productivity is calibrated to $A=\frac{y_{0}}{K_{0}^{\alpha}}=327$, and the emission intensity is $\delta=\frac{3.92 \times 35}{K_{0}^{\theta}}=1.165$.

The total abatement cost is $\mathcal{A}_{t+j}=\lambda \mu^{\phi} \delta K_{t+j}^{\theta}$. We set $\phi=2.5 . \quad \lambda$ is calibrated such that it costs $5.4 \%$ of GDP to abate all emissions today (Nordhaus 2008). Recall $\delta=\frac{3.92 \times 35}{K_{0}^{\theta}}$, so $\lambda=\frac{\mathcal{A}_{0}}{\delta K_{0}^{\theta}}=\frac{0.054 y_{0}}{\delta K_{0}^{\theta}}=$ $\frac{0.054 \times 2200}{3.92 \times 35}=0.866$. 


\section{J Algorithm for the computations}

Given the abatement policy $\mu$ initiated in $t$, we first want to figure out the path of taxes $\left\{\tau_{t+j}^{K}\right\}_{j=0}^{\infty}$. The initial old, generation $t-1$, consume their savings from young. Pareto criterion requires the interest rate cannot be lower, that is, $R_{t} \geq R_{t}^{B A U}$. Since $R_{t}=H\left(S_{t}\right) F_{K}\left(K_{t}\right)-\tau_{t+j}^{K}$, and $S_{t}=S_{t}^{B A U}, K_{t}=K_{t}^{B A U}$, we can only set $\tau_{t}^{K}=0$, which implies $R_{t}=R_{t}^{B A U}$, and the utility of the initial old is held at the BAU level. We use the following steps to calculate the dynamics for $j>0$.

Step 1: at the beginning of $t+j(j \geq 0), S_{t+j}, K_{t+j},, B_{t+j-1}$ and $\tau_{t+j}^{K}$ are given. $w_{t+j}, R_{t+j}, S_{t+j+1}$, and $B_{t+j}$ are given by

$$
\begin{aligned}
& w_{t+j}=(1-\alpha) H\left(S_{t+j}\right) A K_{t+j}^{\alpha} . \\
& R_{t+j}=\alpha H\left(S_{t+j}\right) A K_{t+j}^{\alpha-1}-\tau_{t+j}^{K} . \\
& S_{t+j+1}=(1-\epsilon) S_{t+j}+(1-\mu) G\left(K_{t+j}\right) . \\
& B_{t+j}=R_{t+j} B_{t+j-1}+\Lambda(\mu) G\left(K_{t+j}\right)-\tau_{t+j}^{K} K_{t+j} .
\end{aligned}
$$

Step 2: using Pareto-improving condition

$$
\widetilde{U}_{t+j}\left(w_{t+j}, R_{t+j+1}\right)=\widetilde{U}_{t+j}^{B A U}+\eta_{t+j}\left|\widetilde{U}_{t+j}^{B A U}\right|, \eta_{t+j} \geq 0
$$

we solve $R_{t+j+1}$, and then the saving function $s_{t+j}\left(w_{t+j}, R_{t+j+1}\right)$ is known.

Step 3: calculate $K_{t+j+1}$ and $\tau_{t+j+1}^{K}$ using

$$
\begin{aligned}
& K_{t+j+1}=s_{t+j}-B_{t+j} . \\
& \tau_{t+j+1}^{K}=\alpha H\left(S_{t+j+1}\right) A K_{t+j+1}^{\alpha-1}-R_{t+j+1} .
\end{aligned}
$$

If $\tau_{t+j+1}^{K}<0$, i.e., the economy cannot achieve the required utility improvement without transfers, then we set $\tau_{t+j+1}^{K}=0$. In that case, we need to re-calculate $K_{t+j+1}$. Since $S_{t+j+1}$ and $B_{t+j}$ are known, the capital stock $K_{t+j+1}$ can be solved from $\left(\tau_{t+j+1}^{K}=0\right)$ :

$$
K_{t+j+1}=\frac{(1-\alpha) H\left(S_{t+j}\right) A K_{t+j}^{\alpha}}{1+\beta^{-\frac{1}{\sigma}}\left(\alpha A H\left(S_{t+j+1}\right) K_{t+j+1}^{\alpha-1}\right)^{1-\frac{1}{\sigma}}}-B_{t+j} .
$$




\section{References}

[1] Barrage, Lint. "Climate Change Adaptation vs. Mitigation: A Fiscal Perspective." (2015).

[2] Bovenberg, A. Lans, and Ben J. Heijdra. "Environmental tax policy and intergenerational distribution." Journal of Public Economics 67.1 (1998): 1-24.

[3] —. "Environmental abatement and intergenerational distribution." Environmental and Resource Economics 23.1 (2002): 45-84.

[4] Burke, Marshall, Solomon M. Hsiang, and Edward Miguel. "Global non-linear effect of temperature on economic production." Nature (2015).

[5] Dao, Nguyen Thang, and Julio Davila. "Implementing steady state efficiency in overlapping generations economies with environmental externalities." Journal of Public Economic Theory 16.4 (2014): 620-649.

[6] Burghaus, Kerstin, Thang Nguyen Dao, and Ottmar Edenhofer. "Self-enforcing intergenerational social contract as a source of Pareto improvement and emission mitigation." Annual Conference 2015 (Muenster): Economic Development-Theory and Policy. No. 113135. Verein fur Socialpolitik/German Economic Association, 2015.

[7] Dell, Melissa, Benjamin F. Jones, and Benjamin A. Olken. "Temperature shocks and economic growth: Evidence from the last half century." American Economic Journal: Macroeconomics 4.3 (2012): 66-95.

[8] Diamond, Peter A. "National debt in a neoclassical growth model." The American Economic Review 55.5 (1965): 1126-1150.

[9] Farmer, Karl, and Birgit Bednar-Friedl. Intertemporal resource economics: An introduction to the overlapping generations approach. Springer Science \& Business Media, 2010.

[10] Fodha, M., Seegmuller, T. 2014. Environmental quality, public debt and economic development. Environmental and Resource Economics, 57(4), 487-504.

[11] Foley, Duncan K. "The economic fundamentals of global warming." October (New York, Department of Economics, New School for Social Research) (2007).

[12] Gerlagh, Reyer, and Michiel A. Keyzer. "Sustainability and the intergenerational distribution of natural resource entitlements." Journal of Public Economics 79.2 (2001): 315-341.

[13] Goenka, Aditya, Saqib Jafarey, and William Pouliot. Pollution, mortality and optimal environmental policy. No. 12-05. 2012.

[14] Gutierrez, Maria-Jose. "Dynamic inefficiency in an overlapping generation economy with pollution and health costs." Journal of Public Economic Theory 10.4 (2008): 563-594. 
[15] Heal, Geoffrey. "Climate economics: a meta-review and some suggestions for future research." Review of Environmental Economics and Policy 3.1 (2009): 4-21.

[16] Heutel, Garth. "How should environmental policy respond to business cycles? Optimal policy under persistent productivity shocks." Review of Economic Dynamics 15.2 (2012): 244-264.

[17] Hoel, Michael, Sverre AC Kittelsen, and Snorre Kverndokk. "Pareto Improving Climate Policies: Distributing the benefits across generations and regions." (2015).

[18] Howarth, Richard B., and Richard B. Norgaard. "Environmental valuation under sustainable development." The American Economic Review 82.2 (1992): 473-477.

[19] John, Andrew, and Rowena Pecchenino. "An overlapping generations model of growth and the environment." The Economic Journal (1994): 1393-1410.

[20] Jouvet, Pierre-Andre, Philippe Michel, and Jean-Pierre Vidal. "Intergenerational altruism and the environment." The Scandinavian Journal of Economics 102.1 (2000): 135-150.

[21] Karp, Larry, and Armon Rezai. "The political economy of environmental policy with overlapping generations." International Economic Review 55.3 (2014): 711-733.

[22] —. Asset prices and climate policy. Technical report, mimeo, 2014.

[23] Kolbert, Elizabeth. "The island in the wind." The New Yorker 7 (2008): 68-77.

[24] Leach, Andrew J. "The welfare implications of climate change policy." Journal of Environmental Economics and Management 57.2 (2009): 151-165.

[25] Murty, Sushama, R. Robert Russell, and Steven B. Levkoff. "On modeling pollution-generating technologies." Journal of Environmental Economics and Management 64.1 (2012): 117-135.

[26] Neumayer, Eric. "A missed opportunity: The Stern Review on climate change fails to tackle the issue of non-substitutable loss of natural capital." Global environmental change 17.3 (2007): 297-301.

[27] Nordhaus, William D. A Question of Balance: Weighing the Options on Global Warming Policies. Yale University Press, 2008.

[28] Nordhaus, William D. "A review of the Stern review on the economics of climate change." Journal of economic literature 45.3 (2007): 686-702.

[29] Pearson, Charles S. Economics and the challenge of global warming. Cambridge University Press, 2011.

[30] Poutvaara, Panu. "Gerontocracy revisited: unilateral transfer to the young may benefit the middleaged." Journal of Public Economics 88.1 (2004): 161-174. 
[31] Rasmussen, Tobias N. "Modeling the economics of greenhouse gas abatement: An overlapping generations perspective." Review of Economic Dynamics 6.1 (2003): 99-119.

[32] Rezai, Armon. "Recast the DICE and its policy recommendations." Macroeconomic Dynamics 14.S2 (2010): 275-289.

[33] Sachs, Jeffrey D. "Climate change and intergenerational well-being." The Oxford Handbook of the Macroeconomics of Global Warming (2014): 248-259.

[34] Stern, Nicholas Herbert. The economics of climate change: the Stern review. Cambridge University Press, 2007.

[35] von Below, David, Francis Dennig, and Niko Jaakkola. "The climate debt deal: an intergenerational bargain." (2015).

[36] Wang, Min, Jinhua Zhao, and Joydeep Bhattacharya. "Optimal health and environmental policies in a pollution-growth nexus." Journal of Environmental Economics and Management 71 (2015): 160-179. 